This item was submitted to Loughborough's Research Repository by the author.

Items in Figshare are protected by copyright, with all rights reserved, unless otherwise indicated.

\title{
Sustainable agro-food supply chain design using two-stage hybrid multi- objective decision-making approach
}

PLEASE CITE THE PUBLISHED VERSION

http://dx.doi.org/10.1016/j.cor.2016.10.012

PUBLISHER

(C) Elsevier

VERSION

AM (Accepted Manuscript)

\section{PUBLISHER STATEMENT}

This work is made available according to the conditions of the Creative Commons Attribution-NonCommercialNoDerivatives 4.0 International (CC BY-NC-ND 4.0) licence. Full details of this licence are available at: https://creativecommons.org/licenses/by-nc-nd/4.0/

\section{LICENCE}

CC BY-NC-ND 4.0

\section{REPOSITORY RECORD}

Allaoui, Hamid, Yuhan Guo, Alok Choudhary, and Jacqueline Bloemhof. 2016. "Sustainable Agro-food Supply Chain Design Using Two-stage Hybrid Multi-objective Decision-making Approach”. Loughborough University. https://hdl.handle.net/2134/23085. 


\title{
Sustainable Agro-Food Supply Chain Design Using Two-Stage Hybrid Multi- Objective Decision-Making Approach
}

\author{
Hamid Allaoui $^{1}$, Alok Choudhary ${ }^{2 *}$, Yuhan Guo ${ }^{1}$, Jacqueline Bloemhof ${ }^{3}$ \\ ${ }^{1}$ Univ. Artois, EA 3926, Laboratoire de Génie Informatique et d'Automatique de l'Artois (LGI2A) Béthune, \\ F-62400, France \\ 2 Management Science and Operations Management Group, School of Business and Economics, \\ Loughborough University, Leicestershire, UK \\ ${ }^{3}$ Operations Research and Logistics, Wageningen University, NL \\ * Communicating authors: a.choudhary@,lboro.ac.uk
}

\begin{abstract}
Sustainability of agro-food supply chains has recently become the subject of greater interest from consumers, firms, governmental organizations and academia as the environment continues to deteriorate. One of the most critical factors influencing the sustainability of an agro-food supply chain is its network design. A particularly challenging aspect in this context is the broad range of influencing indicators associated with the Triple Bottom Line (TBL) of sustainability that need to be considered. However, many of these indicators could not be fully integrated or measured by single-step optimization problems. This paper presents a critical literature review of operational research methods for the design of sustainable supply chains. A novel two-stage hybrid solution methodology is proposed. In the first stage, a partner selection is performed using a hybrid multi criteria decision making based on Analytic Hierarchy Process (AHP) method and the Ordered Weighted Averaging (OWA) aggregation method. The result obtained in the first stage is used in the second stage to develop a multi-objective mathematical model to optimize the design of the supply chain network. This approach allows the simultaneous consideration of all three dimensions of sustainability including carbon footprint, water footprint, number of jobs created and the total cost of the supply chain design. The proposed approach generates a Pareto frontier to aid users in making decisions. Numerical experiments are completed utilizing data from a case study of French agro-food company to demonstrate the efficiency and effectiveness of the solution method. The analyses of the numerical results provide important organizational, practical and policy insights on (1) the impact of financial and environmental sustainability on supply chain network design (2) the use of environmental emission, water footprint, societal and cost tradeoff analysis for making informed decision on supply chain investment.
\end{abstract}

Keywords: Agro-food supply chain design, sustainability, decision-making, multi-objective optimization, Analytical Hierarchy Process. 


\section{Introduction}

Growing environmental, social, and ethical concerns and increased awareness of the effects of food production and consumption on the natural environment have led to increased pressure from consumer organizations, environmental advocacy groups, policy makers, and several consumer groups on agro-food companies to deal with the sustainability of their supply chains. Interest in sustainability of supply chains has grown over the last decade. Achieving sustainability entails reaching a balance of economic growth, environmental protection and social conditions. Therefore, a sustainable supply chain refers to the ways in which organizational innovations and policies in supply chain management are considered in the context of sustainable development [46],[1]. It is imperative to consider sustainability in agro-food supply chain, since it relates to marked environmental and social impacts. In 2010, the International Resource Panel of the United Nations Environment Programme found that agriculture and food consumption are two of the most important drivers of environmental pressures including habitat change, climate change, water use and toxic emissions [32].

Most of the current research focuses on the improvement of individual firms or processes rather than the design of an entire supply chain. Although considerable effort has been put into researching efficiency and economic performance measures, there is very little research available concerning the influence of all three dimensions of sustainability and decisions on agro-food supply, which could, in turn, offer managers the prescriptive models required to create a sustainable agro-food supply chain. Some of the more rigorous attempts at Sustainable Supply Chain Management (SSCM) modeling have been conducted in 'closing--loop' or reverse logistics literature [19]. Yet, much of that literature has focused on cost-based measures or traditional financial metrics optimization, e.g. revenue generation or cost reduction. Interestingly, in many of these models, environmental measures play a minor role, if any, to operational and financial measures [63]. Some other research efforts have started to narrow the gaps in formal modeling literature by investigating specific aspects of SSCM [22], [58]. Such modeling efforts are limited, not because of the insignificance of the work but because of the complexities involved in SSCM.

Agro-food supply chain network design becomes more challenging when sustainability is embraced in the traditional economic-oriented models. One of the main challenges in this context 
is the broad range of influencing factors associated with sustainability that need to be considered, many of which could not be fully integrated or measured in single step optimization problems. To achieve this goal, synergies must be created between economic growth, environmental protection and social conditions, with a multidisciplinary scientific and technical approach. Although there has been some work done to identify the attributes of sustainability in agro-food supply chain, little effort has been offered to come up with a holistic framework.

This paper intends to address this gap. Indeed, very few papers so far have considered all three dimensions of sustainability in designing an agro-food supply chain using an optimization approach. Decision-making tools and techniques can help organizations make more effective and informed sustainable agro-food supply-chain design decisions. To help advance this research and further integrate sustainability into agro-food supply chain network modeling, this research proposes a two-stage hybrid solution methodology. First, this will perform a partner selection of an agro-food supply chain with a number of sustainability indicators (Stage I), and second this will formulate a mathematical model with multiple objective functions to optimize the design of the supply chain, and generate a Pareto frontier to aid users in making decisions (Stage II). To the best of our knowledge, this paper is the first to take into consideration water footprint, $\mathrm{CO} 2$ footprint and the number of jobs created along with economic cost in terms of multi-objective optimization for designing sustainable four echelons supply chains. Furthermore, this research investigates the application of the proposed method using an illustrative case study to show the efficiency and effectiveness of our approach.

The remainder of this paper is organized as follows. In section 2, a systematic review of operational research tools and methods for the design of sustainable supply chains is presented. From a performance perspective, we make a distinction between papers focusing on a single criterion and papers that focus on multiple criteria. Section 3 then presents the hybrid two-stage approach to design the sustainable agro-food supply chain. A multi-criteria decision-making method is presented in the first stage, followed by an introduction of the mathematical formulations and the solution method of the second stage. Section 4 presents a case study of an agro-food supply chain to illustrate the application of the proposed methodology. Managerial implications are also discussed in this section. Finally, the paper concludes with a note about future research in section 5 . 


\section{Background and literature review}

\subsection{Sustainable Agro-Food Supply Chains}

Despite the agro-food sector's importance for the development of any economy, its supply chains have received little attention in the literature. One of the main reasons for this neglect may be characteristics of agro-food products and processes. Agro-food supply chains are complex systems involving multiple firms usually working together within specific industry sectors to satisfy an increasingly globalized market demand for food products. Recently, consumers have become more inquisitive and there is growing concern over food attributes such as quality, integrity, safety, diversity and sustainability. To meet these requirements, companies have begun to incorporate sustainability concerns in the management of their operations in line with corporate social responsibility [26-28]. Thus, the design and management of agro-food supply chains has become extremely important in determining where a competitive advantage could be gleaned for the companies and/or industries involved [14]. The agro-food supply chain refers to a series of activities from production to distribution that brings agricultural or horticultural products from the farm to the kitchen table. The roles in an agro-food supply chain usually include the sectors responsible for producing the raw materials (farmers), processing and transforming raw materials into products, and ultimately distributing and delivering final products to the final consumers [5].

As is the case with any supply chain, the agro-foods supply chain is a network of different sectors working together in different processes and activities in order to bring products and services to the market, with the purpose of satisfying client' demands. However, what distinguishes the agrofood supply chain from other supply chains is the importance of indicators such as food quality, safety, weather-related variability and limited shelf life of products [59]. These indicators make the agro-food supply chain more complex and harder to manage than the others.

The network of the supply chain considered in this paper is shown in Figure 1. This supply chain consists of four levels: suppliers who are farmers, transformer sites, distributor sites, and clients who are retailers. The developed multi-objective linear supply chain model aims to select effective suppliers from a candidate set of suppliers, and to locate a given number of effective transformers, and distributors to satisfy the demands of the client. This is done in order to minimize the overall supply chain cost considering economic, environment, and social aspects, subject to supplier, transformer and distributor capacity constraints. 


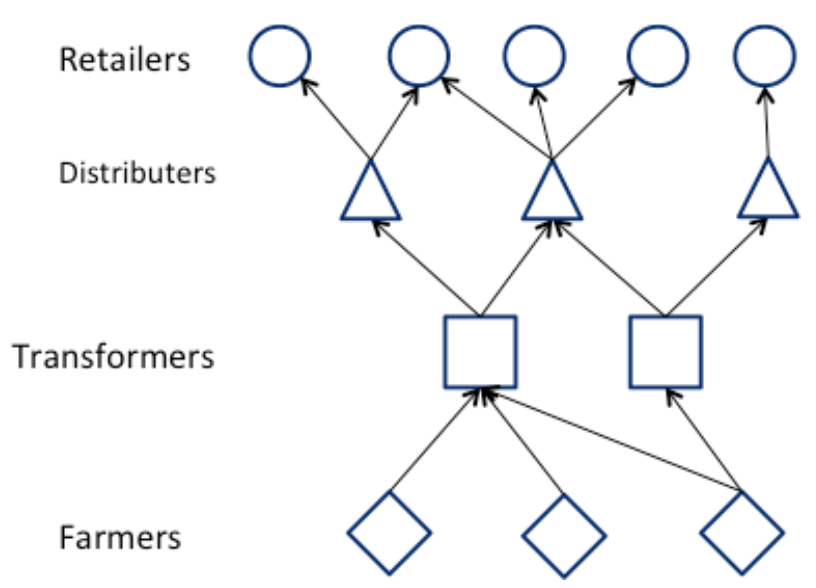

Figure 1: Structure of the supply chain considered in this paper

The agro-food industry is one of the biggest users of road freight and the volume of road freight transport is growing constantly (accounting for over $80 \%$ of goods moved in the UK), with obvious disadvantages in congestion, safety and pollution. Large Goods Vehicles are responsible for around $25 \%$ of the Europe's road transport CO2 emissions [45].

In EU the food and drink sector contributes to $20 \%-30 \%$ of all environmental impacts [8]. According to [60], food systems contribute $19 \%-29 \%$ of global anthropogenic greenhouse gas (GHG) emissions, releasing 9,800-16,900 Mega-tones of carbon dioxide equivalent (MtCO2e) in 2008. Concerning water issues, agricultural sector consumes and pollutes approximately $70 \%$ of the global freshwater resources [57], intensifying global water scarcity [4].

Moreover, global demand for food is forecast to increase by $50 \%$ by 2030 with a consequent increase in demand for resources to produce and transport it, in particular energy and water. This increased demand could have a huge impact on climate change while in turn climate change could have an important influence on the agricultural and food sectors, determining where products are produced and where they have to be transported. Compounded with all this over the longer term could be constraints on water availability and demands for energy to support a growing, wealthier population [45].

\subsection{Literature review on analytical models for sustainable supply chain}

Sustainability initiatives in organizations can be undertaken at strategic, tactical and operational planning levels of decision-making. These decisions may include sustainable supplier selection [7], sustainable supply chain network design [23], sustainable purchasing, sustainable freight transportation, sustainable manufacturing and service provision [25], and sustainable information 
technology. Our focus in this research is on the integration of two important issues: sustainable partner selection and optimization of sustainability performance indicators in agro-food supply chain network design. Within this sector, this topic has so far received little attention; therefore, our research represents an early effort in this regard. Before to investigate existing works in the literature dealing with multi-objective methods, we present most relevant works focusing on agro-food supply chain design. According to an excellent literature review given by [53], few papers addressed design decisions of agro-food supply chains. They stated that despite the significance of strategic decisions and a number of papers that address them within the general supply chain context, the relevant agro-food literature dealing with configuration of agro-food networks is rather limited, probably due to difficulties imposed by the structure and complexity of the relationships of an entire agro-food chain, as well as the incoming uncertainties that characterize this particular type of network. Another finding that can be drawn from the reviewed papers by [52] is that research into agro-food supply chains sustainability has received insufficient attention in literature. For these reasons we decide to review quantitative models dealing with aided decision making methods and tools for supply chain design in the general context.

\subsubsection{Single criterion methods}

Most relevant research deals with single criterion methods focusing heavily on economic measures in sustainable supply chains. Some of these works transform a sustainable problem into an aggregate single criterion. However, the foundation of sustainability is the triple bottom-line approach that seeks to balance economic, environmental and social dimensions. Therefore, the most important works in the literature dealing with multi-criteria methods for supply chain design in a sustainable context are reviewed.

Supply chain design is a combinatorial optimization problem. The objective of this particular kind of problem is to find an optimal solution from a finite number of feasible solutions. Various approaches such as Branch-and-Bound, Bender Decomposition, and Lagrangian Relaxation [21] have been proposed concerning solving supply chain design problems with financial measures as an objective function taken into consideration. However, most of these methods do not provide feasible solutions when the size of the problem increases. For larger instances, exact methods fail because the size of the solution space increases exponentially with the number of constraints and variables in the network. As a result, the computation time of the exact methods has become impractical in solving real life problems. In these cases, heuristic or meta-heuristic methods can be used to produce near optimal solutions in a reasonable computational time. 
[41] proposed a mixed integer programming formulation for multi-commodity, multi-plant, distribution system design problems. The objective is to minimize the total operating costs of the distribution network. The authors presented an efficient heuristic based on the Lagrangian Relaxation method to solve the problem. [17] presented a large-scale network design model for the outbound supply chain of an automotive company. The most important characteristics mentioned in the paper are lead times and choice of transportation mode. To solve this large-scale design model, a Lagrangian heuristic is presented. The algorithm offers excellent solution quality in modest computational time. [4],[17],[31],[44],[39],[51],[36] explicitly applied this method to solve their models. Other works existing in the literature deal with operational and tactical planning of supply chains [48],[49],[50].

[2] and [18] conducted an exhaustive review of the application of planning models in the agrofood supply chain and mainly focused on the models that have been successfully implemented. Overall, they classified the modeling approaches for agro-food supply chain into deterministic methods such as linear programming, dynamic programming, mixed integer programming, and goal programming, and stochastic methods such as stochastic programming, stochastic dynamic programming, simulation, and risk programming. They concluded that the modeling efforts in agro-food supply is still lagging behind the research aimed at automotive or manufacturing supply chains and highlighted the essence of conducting research in the domain of agro-food supply considering sustainability dimensions.

Most of the abovementioned literature has focused on single cost based measures, or traditional financial metrics, e.g. revenue generation, cost reduction, profit maximization or lead time reduction. In addition, most of these studies also focused on a single activity within the supply chain such as warehousing, production management, inventory optimization or transportation. In the next section, multiple criteria methods used in literature for sustainable supply chain will be discussed.

\subsubsection{Multiple criteria methods}

In the context of sustainable supply chain, the decision maker likes to consider financial, environmental and social issues simultaneously. Such a relatively new desire transforms the decision-making problem into a Multi-Criteria Decision Making (MCDM) problem. Recently, there has been growing pressure on supply chain partners to reduce the levels of their carbon emissions. [47] presented an integrated approach for selecting appropriate suppliers in the supply chain, addressing the carbon emission issue, using fuzzy-AHP and fuzzy multi-objective linear 
programming. Meanwhile [42] proposed a multi-objective fuzzy mathematical programming model for designing an environmental supply chain under inherent uncertainty of input data with regard to such a problem.

In solving MCDM problems, there are several approaches to finding the Pareto-optimal front of a multi-objective problem. For a comprehensive study of these approaches, readers may refer to [11]. [37] proposed a decision-support tool based on a mixed integer linear model for the design of sugarcane supply chains (SC) considering the minimization of the total supply chain costs and environmental impact. [35] used MILP model and production, distribution, and capacity planning of a global supply chain while considering three objectives: cost, responsiveness and customer service level. The $\varepsilon$-constraint method generates a set of Pareto-optimal solutions. A bi-objective linear programming model was formulated and solved generating the Pareto Frontier and highlighting the trade-off conditions that make the system profitable with low environmental impact [9], [10].

[33] constructed a goal programming (GP) model to evaluate and select suppliers. Three goals were considered in the model, namely cost, quality, and delivery reliability. To model a multiobjective decision-making problem aiming to select the best warehouses, [62] combined the AHP and goal programming. [29] employed a GP technique for the supply partner selection problem that was able to achieve multiple goals for different levels of performance of the corresponding attributes.

Weighting methods are also commonly used to solve multi-criteria decision-making problems. Simple Multi-Attribute Rating Technique (SMART) was originally described as the whole process of rating alternatives and weighting criteria. The Analytical Hierarchy Process (AHP) method builds on the pair-wise comparison model for determining weights for every unique criterion. AHP was proposed primarily by [43]. [30] presented a waste management problem where Geographical Information Systems (GIS) have been combined with multi-criteria evaluation techniques to take into account public's role in the decision-making process. [54] considered the environmental dimension and included qualitative and quantitative criteria (benefits, opportunities, costs, and risks), in order to assess and to select undesirable facility locations.

[16] proposed a fuzzy systematic approach to extend Technique for Order Preference by Similarity to Ideal Solution (TOPSIS) to solve the supplier selection problem based on supplier profitability, relationship closeness, technological capability, conformance quality, and conflict 
resolution factors. [65] presented a new TOPSIS approach to select plant locations, where the ratings of various locations for each criterion and the weights of various criteria were assessed using fuzzy linguistic terms.

Grey theory was developed by [15] to study the degree of relationship between various criteria in a MCDM problem and is considered a very useful mathematical tool for dealing with system analysis with limited information. [12] used this method to investigate how energy-induced $\mathrm{CO}_{2}$ emissions from 34 industries in Taiwan are affected by production, total energy consumption, coal, oil, gas, and electricity use.

[40] presented an Elimination and Choice Translating Reality (ELECTRE) III method to select the best sites for a waste-disposal plant and an incinerator. The ELECTRE III method was chosen from its family of methods because of the imprecision and uncertainty of some of the available data. The ELECTRE III uses the concept of pseudo criteria 3 and fuzzy outranking procedure.

[13] used Preference Ranking Organization Method for Enrichment Evaluation (PROMETHEE) for outsourcing research and applied it to a midsized Italian firm operating in the field of public road and rail transportation, in order to choose the relevant suppliers. [20] combined PROMETHEE II, III and V, based on fuzzy evaluations, to rank and select distribution centers for a firm in four areas of Belgium.

The potential for integrating MCDM with other analytical methods has been examined by several authors [61]. [34] presented a hybrid method that integrates AHP and SWOT (Strengths, Weaknesses, Opportunities and Threats) analysis. [38] used a hybrid approach to estimate a sustainability index using MCDM and integrated this with system dynamics. [24] introduced an evaluation of hazardous waste transportation firms by using a two-step fuzzy-AHP and TOPSIS methodology. [55] evaluated the environmental performance of suppliers with a hybrid fuzzy multi-criteria decision approach: fuzzy ANP and fuzzy PROMETHEE methodology. In their study, the evaluation criteria were determined as pollution control, green process management, environmental and legislative management, environmental costs, green product, and green image. [6] developed an integrated DEA enhanced Russell measure (ERM) model in fuzzy context to select the best sustainable suppliers. [56] proposed an integrated solution framework that can be used to evaluate both tangible and intangible attributes of potential suppliers. The proposed framework combines three individual methods, namely the fuzzy analytic hierarchy process, fuzzy complex proportional assessment and fuzzy linear programming. 
It is obvious from the abovementioned literature review that the authors were only able to focus on limited criteria in their approaches. Even in multiple criteria decision-making approaches, only a few indicators could be taken into consideration. Limited or no work has been carried out in the area of agro-food supply chain design considering multiple criteria from sustainability dimensions. This paucity is mainly because of the complexity involved in modeling various criteria. Optimization models, due to the additional social and environmental dimensions, in addition to operational business concerns, tend to become complex. Consideration of sustainability dimensions in the agro-food supply chain requires the inclusion of a large number of indicators in the supply chain design. In addition, there are a number of indicators which could not be modeled in a one-stage optimization problem. Noting that this gap exists in the literature, an efficient and effective two-stage hybrid multi-objective decision-making model considering various indicators of sustainability is proposed for agro-food supply chain network design. The next section discusses the two-stage hybrid approach.

\section{Proposed two-step hybrid approach}

As mentioned above, the indicators for a sustainable agro-food supply chain are substantial and complex. In addition, the format of the data can be either numeric or linguistic, adding to the aforementioned complexity. Thus, it is impossible and unrealistic to integrate all indicators into the objective function(s) of a mathematical formulation. In order to take into consideration as many indicators as possible, a two-stage hybrid approach is proposed to design the sustainable agro-food supply chain.

The first stage of this approach entails performing an initial evaluation of partners of a supply chain with several criteria and sub-criteria. The criteria which may be too complex to integrate into an objective function in the second stage can be considered in the first stage. The potential suppliers, transformer sites, and distributor sites are evaluated with different sets of criteria or sub-criteria in order to determine their efficiency score with respect to their performance in the supply chain. The calculation of the efficiency score is performed by a combination of the Analytic Hierarchy Process (AHP) method [43] and the Ordered Weighted Averaging (OWA) aggregation method [64]. This score will be considered and optimized in the second stage as one of the objectives. In addition, an optional filter process is proposed. If the number of partners is too large for optimization in the second stage, the user activates the filter process and as a result the sites with better performance would be selected in the second stage. 
The second stage of this approach involves the application of a mathematical model with multiple objective functions. All three dimensions namely financial, environmental and social, of sustainability, are considered in addition to the efficiency score calculated in the first stage. As shown in Figure 1, both the carbon footprint and water footprint are considered as the environmental dimension. Finally, a Pareto front is generated to aid the user's decision making. The stepwise structure of our hybrid approach is shown in Figure 2.

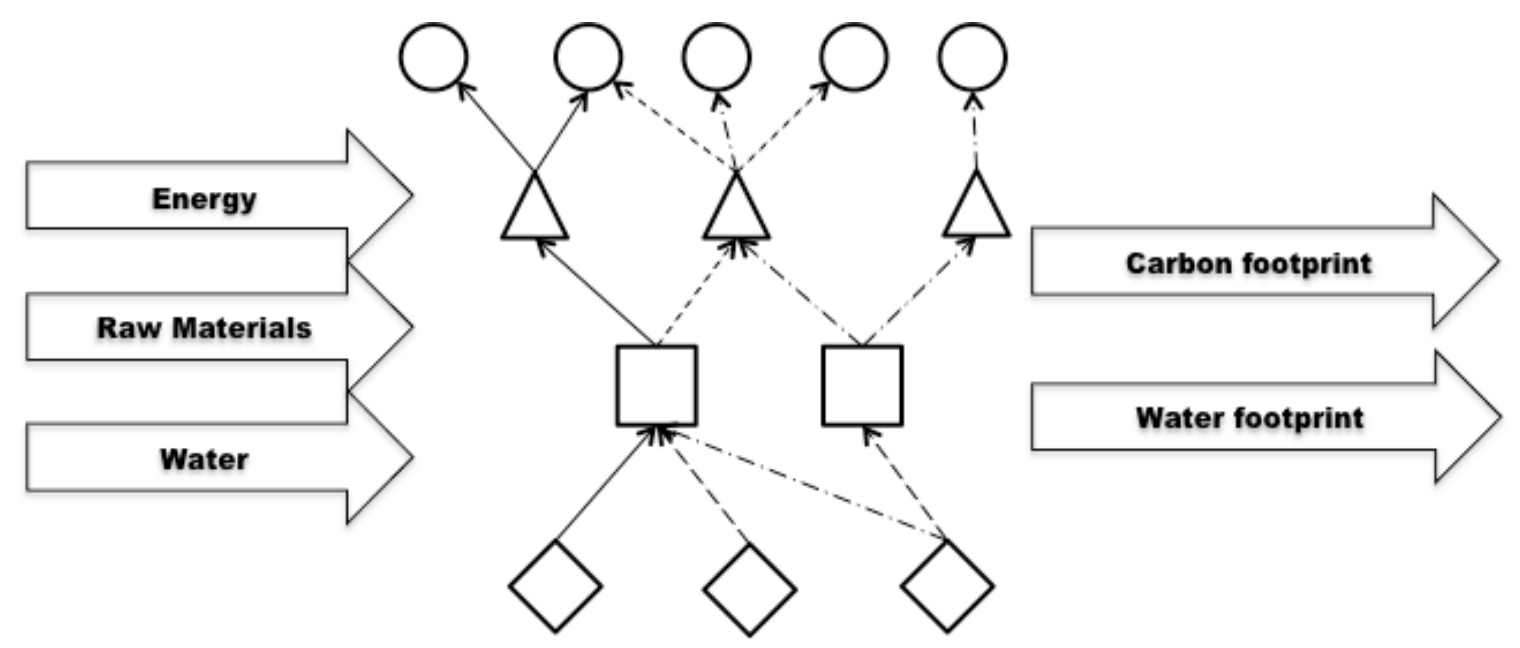

Figure 2: Environmental aspect considered in stage two

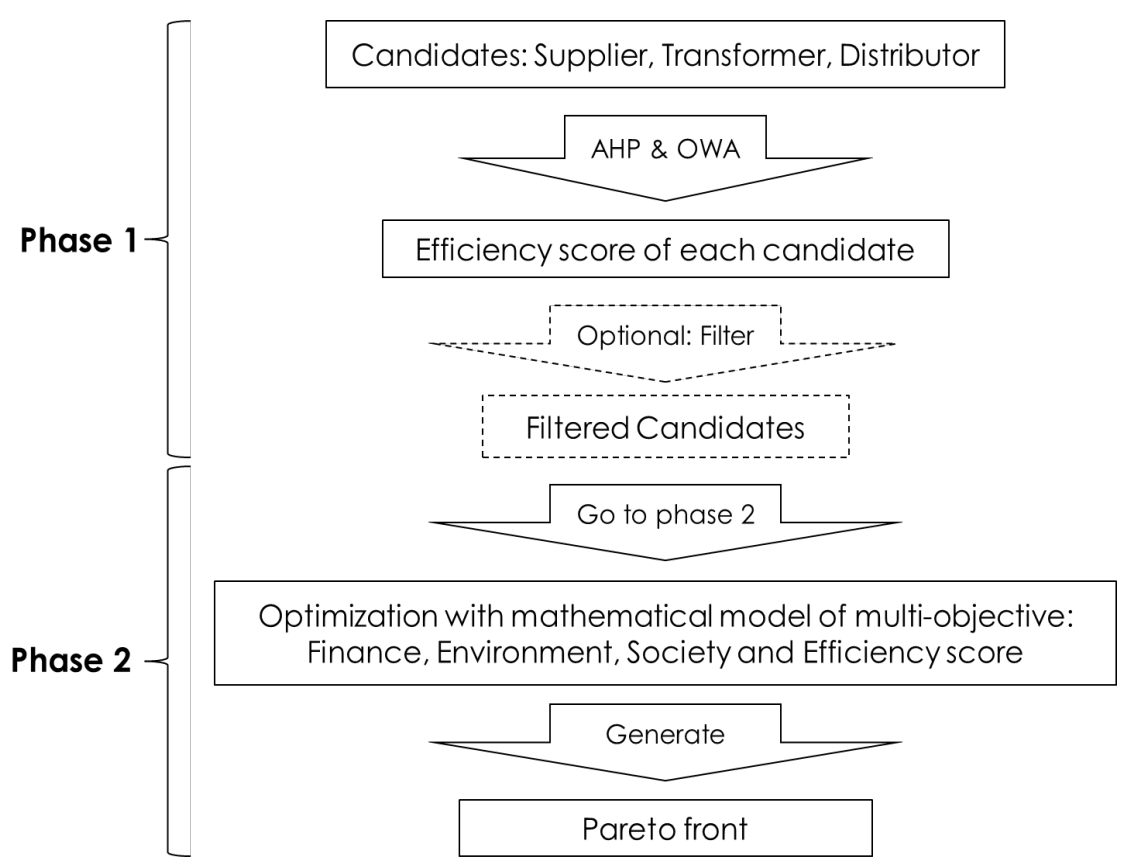

Figure 3: Structure of our hybrid approach 


\subsection{Stage one: Application of AHP and OWA}

The evaluation criteria for this stage encompass the supply chain process, and include a range of performance indicators and activity measures as shown in Table 1. The AHP method is used to obtain a weight for each of these selected criteria indicating their importance levels. Then, as each of these criteria has an associated importance, one is able to calculate an overall aggregated efficiency score for each potential partner in the supply chain with OWA aggregation method. In this way, the potential partners are evaluated separately according to specified criteria, and the decision maker can decide if a filter process is needed before starting the second stage.

\begin{tabular}{c|c|c}
\hline Economy & Environment & Society \\
\hline & Land usage & \\
Product price & Recyclability & Worker satisfaction \\
Product quality & Reusability & Food safety \\
Sustainability investment & Use of fertilizers & Risk of accidents \\
Training cost & Generated waste & Fair trade \\
Output growth & Water polluted & Recruitment \\
Added value & Pollution prevention & Safety training \\
Renewable resources & Hazardous material volume & Social equity \\
Productivity & Toxic substances & \\
& & \\
\hline
\end{tabular}

Table 1: Indicators used in stage 1

It should be noted that the AHP and OWA methods do not operate at the same level. The AHP is a global tool for creating a hierarchical model for the spatial decision making problem by analyzing the whole process and evaluating each alternative. The OWA operators, alternatively, provide a general framework for making a series of local aggregations used in the AHP.

As in the AHP procedure, one begins this stage by structuring the hierarchy. This step consists of the creation of the decision hierarchy by structuring the decision problem into a hierarchy of decision elements, generally starting from the most general objectives to the most specific one. The last level of the hierarchy contains the candidates. In the context of this paper, four-level hierarchies of problem, criteria, indicators (as in Table 1) and candidates have been considered. Figure 3 presents an example of the hierarchical structures considered in our approach. 


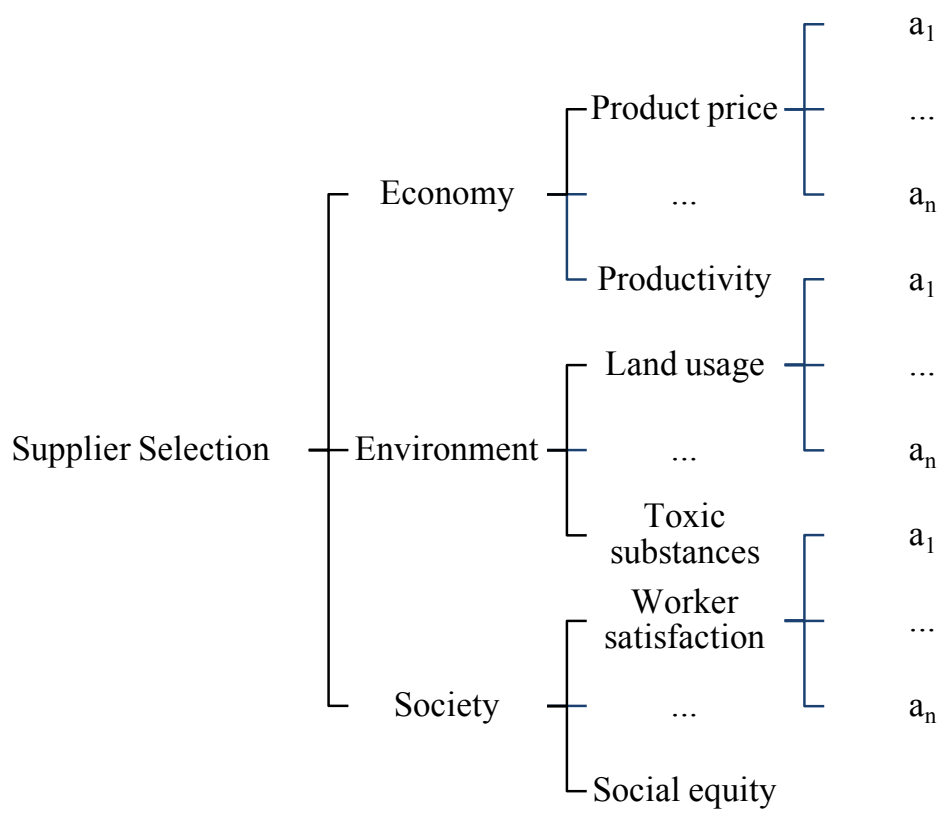

Figure 3: Hierarchical structure of the decision problem

The AHP allows the weights to be assigned through pairwise comparisons of the elements emerging from a node of the hierarchy with regard to the parent node. All these pairwise comparisons are stored in matrices. The eigenvector associated with each pairwise comparison matrix represents the relative weights of the indicators. Let us assume that there are $n$ indicators present to an observer. The goal of the observer is to:

(1) Provide judgments on the relative intensity of these indicators;

(2) Ensure that the judgments are quantified.

A set of weights can be associated with an individual indicator derived from the observer's quantified judgments (i.e., from the relative values associated with pairs of indicators). These weights should reflect the individual's quantified judgments. Using this approach, the information resulting from (1) and (2) can be put into a usable form without deleting information residing in the qualitative judgments. Let $A_{1}, A_{2} \ldots A_{n}$, be the set of indicators. The quantified judgments on pairs of indicators $A_{i}, A_{j}$, are represented by an n-by-n matrix $A=\left(a_{i j}\right) ; i, j=1,2 \ldots n$. The entries $\mathrm{a}_{\mathrm{ij}}$ are defined by the following entry rules:

Rule 1: If $a_{i j}=x$, then $a_{j i}=1 / x(x=1,2 \ldots 9)$.

Rule 2: If $A_{i}$ is judged to be of equal relative intensity to $A_{j}$, then $a_{i j}=a_{j i}=1$. 


\section{Rule 3: $a_{i i}=1$ for all $i$.}

Thus, the matrix A takes the following form:

$$
A=\left[\begin{array}{cccc}
1 & a_{12} & \ldots & a_{1 n} \\
1 / a_{12} & 1 & \ldots & a_{2 n} \\
\vdots & \vdots & \vdots & \vdots \\
1 / a_{1 n} & 1 / a_{2 n} & \ldots & 1
\end{array}\right]
$$

In the judgment matrix $\mathrm{A}$, a single number is assigned to each $\mathrm{a}_{\mathrm{ij}}$. This number is a nearest integer approximated to the relative intensity between $A_{i}$ and $A_{j}$. The numbers 3,5, 7, and 9 correspond to the verbal judgments "moderately more dominant", "strongly more dominant", "very strongly more dominant", and "extremely more dominant" (with 2, 4, 6, and 8 for compromise between the previous values). Reciprocal values are automatically entered in the transpose position. Thereafter, the weight vector of matrix $\mathrm{A}$ is calculated. The values in the weight vector are the corresponding weight value for the indicators.

Now each of the indicators has an associated importance. The aggregation process in a classic AHP uses a simple weighted average for calculating the final scores. The OWA operators, on the other hand, present a parameterization, which allows the decision maker to go from one extreme of requiring "all the criteria" to the other extreme of requiring "one criterion" and includes the case of taking the average of the criteria scores. At this point, the quantifier guided OWA procedures take the lead for the rest of the analysis. The procedure at this stage involves three main steps: (1) Specifying the linguistic quantifiers Q, (2) generating new weights for candidates, and (3) computing the overall efficiency score for each candidate, at each level of the hierarchy, by using the OWA combination function.

In our problem, some indicators are more important than others and a better candidate means the one which has higher scores on most of the indicators. Thus, one selects the "most" quantifier $Q(r)=r^{2}$.

Let us assume that $\left\{A_{1}, \ldots, A_{n}\right\}$ are our indicators, and $V_{i}$ is the importance of each indicator calculated by the AHP method. Let $x_{i} \in X(i=1 . . n)$ be an alternative, $\mathrm{A}_{\mathrm{j}}\left(\mathrm{x}_{\mathrm{i}}\right)$ be the performance score of $x_{i}$ under indicator $A_{j}$. Since the scores under different indicators differ in both unit and format, they should be normalized before using the OWA approach. Two ways for normalizing the scores are proposed, equation 1 is used for numeric values while equation 
2 and 3 are used for linguistic values, where $n$ is the amount of candidates and $\mathrm{A}_{\mathrm{j}}{ }_{\mathrm{j}}\left(\mathrm{x}_{\mathrm{i}}\right)$ is the normalized performance score of $x_{i}$ under indicator $A_{j}$.

$$
\begin{gathered}
A_{j}^{\prime}\left(x_{i}\right)=\left(\frac{A_{j}\left(x_{i}\right)}{\sum_{k=1}^{n} A_{j}\left(x_{k}\right)}\right)^{2} \\
A_{j}^{\prime}\left(x_{i}\right)=\left\{\begin{array}{l}
1(\text { Yes }) \\
0(\text { No })
\end{array}\right. \\
A_{j}^{\prime}\left(x_{i}\right)= \begin{cases}1(\text { Very good }) \\
0.75 & (\text { Good }) \\
0.5(\text { Average })\end{cases}
\end{gathered}
$$

Then, one proceeds with the OWA procedure. First, for each candidate $\mathrm{x}, A_{i}(x)$ is reordered such that $b_{j}$ is the $\mathrm{j}^{\text {th }}$ largest element of the $\left\{A_{1}(x), \ldots, A_{n}(x)\right\}$. Furthermore, let $u_{j}$ denote the importance associated with the attribute that has the $\mathrm{j}^{\text {th }}$ largest satisfaction.

Now, an OWA operator can be constructed of dimension $n$ with weighting vector defined by equation 4 to 7 as follows.

$$
w_{j}(x)=Q\left(\frac{\sum_{k=1}^{j} u_{k}}{T}\right)-Q\left(\frac{\sum_{k=1}^{j-1} u_{k}}{T}\right)
$$

where

$$
T=\sum_{k=1}^{n} u_{k}
$$

and

$$
\begin{gathered}
Q(r)=r^{2} \\
D(x)=\sum_{j=1}^{n} b_{j} w_{j}(x)
\end{gathered}
$$

The evaluation is performed separately for each partner of the supply chain. If a filter process is activated, a percentage $m$ of potential suppliers, transformer sites, and distributor sites will be selected based on their efficiency scores to enter the next stage, otherwise, all potential partners will enter the second stage along with their efficiency score. Finally, the efficiency score is calculated here is considered in the mathematical modeling (see equation 10) in the second stage. 


\subsection{Stage Two: Multi-objective optimization}

The second stage deals with a multi-objective optimization problem. The developed multiobjective linear supply chain model aims to select effective suppliers from a candidate set of suppliers, as well as to locate a given number of effective transformers and distributors, to satisfy the demand requirements of the client, in order to minimize the overall supply chain cost while considering economic, environment, and social aspects, subject to satisfying supplier (farmer), transformer and distributor's capacity constraints.

\subsubsection{Definitions}

Let us first give the definition of such kind of problems and the definition of Pareto optimality [66]:

$$
\begin{array}{cc}
\min f(x)= & {\left[f_{1}(x), \ldots, f_{p}(x)\right]^{T}} \\
\text { S.t. } & h(x)=0 \\
& g(x) \leq 0 \\
& x \in X
\end{array}
$$

Definition: A point $\mathrm{x}^{*} \in \mathrm{X}$ is Pareto optimal (also referred to as efficient or non-dominated) if and only if there does not exist another point $\mathrm{x} \in \mathrm{X}$ such that $\mathrm{f}(\mathrm{x}) \leq \mathrm{f}\left(\mathrm{x}^{*}\right)$ and $\mathrm{f}_{\mathrm{i}}(\mathrm{x})<\mathrm{f}_{\mathrm{i}}\left(\mathrm{x}^{*}\right)$ for at least one objective function $\mathrm{f}_{\mathrm{i}}$. All these solutions feature the property that it is not possible to find another one that improves any of them in one objective without worsening at least one of the others. The set of these solutions is given by a set of points known as the Pareto front. 


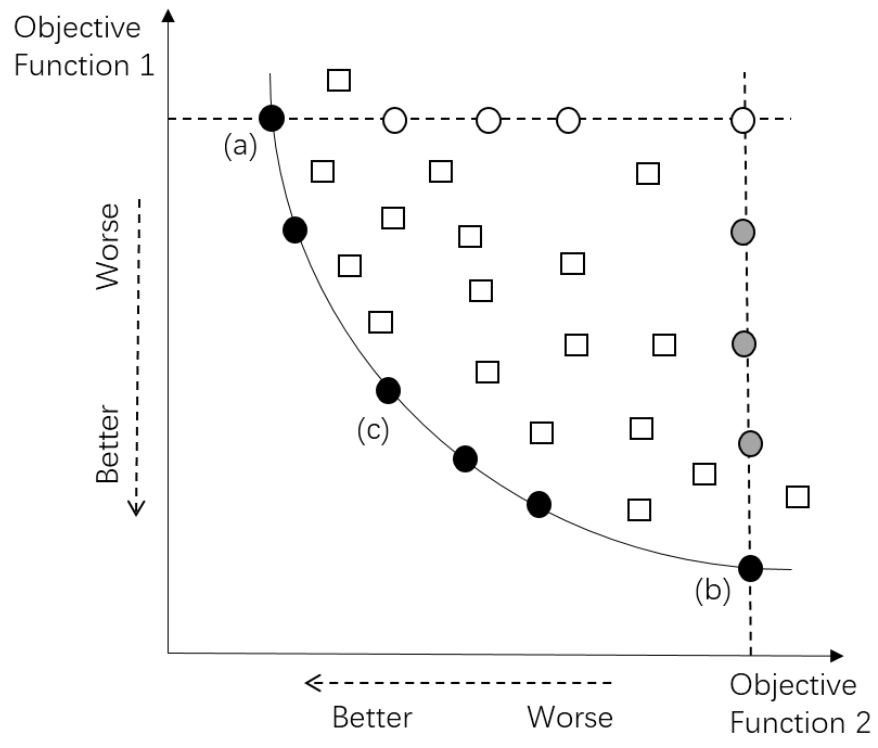

Figure 4: A demonstration of the Pareto front

Figure 4 presents an example of the Pareto front. Full black points indicate members of the Pareto front set. Point (a) is the optimum of objective function F2 for a given value of objective function F1 (compared to empty points). Point (b) minimizes F1 for a given value of F2 (compared to gray points). For a member of the Pareto set, say (c), any attempt to improve a goal involves worsening the other. Empty squares are other possible solutions that are worse than those in the Pareto set.

\subsubsection{Sustainability indicators}

In this stage, three objective functions are considered, the first one represents the economic bottom line, second represents the environmental and the social bottom line and the third represents the efficiency score calculated in the earlier section. The corresponding indicators considered in this stage are listed in Table 2. 


\begin{tabular}{|c|c|c|c|}
\hline & Economic & Environment & Social \\
\hline Supplier & $\begin{array}{c}\text { Raw material cost } \\
\text { Transportation cost } \\
\text { Transportation Emission tax }\end{array}$ & Transportation emissions & - \\
\hline Transformer & $\begin{array}{c}\text { Opening / Closing cost } \\
\text { Operational cost } \\
\text { Production cost } \\
\text { Capacity change cost } \\
\text { Transportation cost } \\
\text { Transportation Emission tax } \\
\text { Energy cost }\end{array}$ & $\begin{array}{l}\text { Production emissions } \\
\text { Operational emissions } \\
\text { Production water consumption } \\
\text { Operational water consumption } \\
\text { Transportation emissions }\end{array}$ & $\begin{array}{l}\text { Number } \\
\text { of jobs } \\
\text { created }\end{array}$ \\
\hline Distributor & $\begin{array}{c}\text { Opening / Closing cost } \\
\text { Operational cost } \\
\text { Capacity change cost } \\
\text { Transportation cost } \\
\text { Transportation Emission tax } \\
\text { Energy cost }\end{array}$ & $\begin{array}{c}\text { Operational emissions } \\
\text { Operational water consumption } \\
\text { Transportation emissions }\end{array}$ & $\begin{array}{l}\text { Number of } \\
\text { jobs } \\
\text { created }\end{array}$ \\
\hline
\end{tabular}

Table 2: Indicators used in stage 2

Here it is important to note that the water footprint in this model is calculated by multiplying the amount of water used by the Water Stress Index, which is calculated based on a region's annual freshwater availability and its withdrawals.

An important boundary condition for the considered supply chain is that consumer demands should be met. The supply chain is therefore traced backwards, i.e. described from what the consumer wants back through to the raw material supplier.

\subsubsection{Mathematical modelling}

The following decision variables are considered in the supply chain network design problem:

$\begin{array}{ll}\text { Supplier } & i=\{1 \ldots I\} \\ \text { Transformer site } & j=\{1 \ldots J\} \\ \text { Distributor site } & k=\{1 \ldots K\} \\ \text { Client } & l=\{1 \ldots L\} \\ \text { Product } & p=\{1 \ldots P\} \\ \text { Raw } & m=\{1 \ldots M\}\end{array}$


material/Component

Time period

$$
t=\{1 \ldots T\}
$$

Transport mode

$s=\{1 \ldots S\}$

Energy type

$e=\{1 \ldots E\}$

To simplify the equations and to shorten our model, following notations are used:

\begin{tabular}{|c|c|}
\hline $\mathrm{D}_{p l}^{t}$ & Order of product $\mathrm{p}$ by client 1 in period $t$ \\
\hline$B M_{m^{\prime} m}$ & Number of units of raw material m' required to make one unite of component \\
\hline$B M_{m p}$ & Number of units of component $\mathrm{m}$ required to make one unite of product $\mathrm{p}$ \\
\hline$Q S_{m, i}^{t}$ & Supply Capacity of supplier i to supply Raw material m' in period t; \\
\hline$Q L T(D)_{j}$ & Lower bound on the capacity of transformer (distribution) site $\mathrm{j}$; \\
\hline$Q U T(D)_{j}$ & Upper bound on the capacity of transformer (distribution) site $\mathrm{j}$ \\
\hline$Q I C T(D)_{j}$ & Initial capacity of transformer (distribution) site $\mathrm{j}$ at the beginning of the first \\
\hline $\operatorname{IOT}(D)_{j}$ & $\begin{array}{l}\text { Initial state of transformer (distribution) site } \mathrm{j} \text { at the beginning of the first } \\
\text { period (open }=1, \text { close }=0 \text { ); }\end{array}$ \\
\hline$C O(M, F) T(D)_{j e}^{t}$ & $\begin{array}{l}\text { Fixed cost of opening (maintaining, closing) transformer (distribution) site } \mathrm{j} \\
\text { using energy type e in period t; }\end{array}$ \\
\hline$J C_{j}^{t}$ & Amount of jobs created by opening site $\mathrm{j}$ in period $\mathrm{t}$ \\
\hline$C I(M, F) C T(D)_{j}^{t}$ & $\begin{array}{l}\text { Fixed cost of increasing (maintaining, decreasing) one unit of capacity in } \\
\text { transformer (distribution) site } j \text { in period } t\end{array}$ \\
\hline$C S(T, D) T(D, C)_{m i j s}^{t}$ & $\begin{array}{l}\text { Transportation cost of one unit raw material or product } \mathrm{m} \text { from supplier } \\
\text { (transformer, distributor) } \mathrm{i} \text { to transformer (distributor, client) } \mathrm{j} \text { using } \\
\text { transportation method } \mathrm{s} \text { in period } \mathrm{t} \text {; }\end{array}$ \\
\hline$C P P(M)_{p j e}^{t}$ & $\begin{array}{l}\text { Production cost of one unit product (component) } \mathrm{p} \text { in transformer site } \mathrm{j} \text { using } \\
\text { energy type e in period } \mathrm{t} \text {; }\end{array}$ \\
\hline$C S M_{m i}^{t}$ & Purchase cost of one unit raw material $\mathrm{m}$ from supplier $\mathrm{i}$ in period $\mathrm{t}$ \\
\hline$E S(T, D) T(D, C)_{m i j s}^{t}$ & $\begin{array}{l}\text { Emission to transport one unit raw material or product } \mathrm{m} \text { from supplier } \\
\text { (transformer, distributor) } \mathrm{i} \text { to transformer (distributor, client) } \mathrm{j} \text { using } \\
\text { transportation method } \mathrm{s} \text { in period } \mathrm{t} \text {; }\end{array}$ \\
\hline$E P P(M)_{p j e}^{t}$ & $\begin{array}{l}\text { Emission to produce one unit product (component) } \mathrm{p} \text { in transformer site } \mathrm{j} \text { using } \\
\text { energy type e in period } \mathrm{t} \text {; }\end{array}$ \\
\hline$W P P(M)_{p j e}^{t}$ & $\begin{array}{l}\text { Water to produce one unit product (component) } \mathrm{p} \text { in transformer site } \mathrm{j} \text { using } \\
\text { energy type e in period } \mathrm{t} \text {; }\end{array}$ \\
\hline$E P R_{m i}^{t}$ & Emission generated to produce one unit raw material $\mathrm{m}$ from supplier $\mathrm{i}$ in \\
\hline$W P R_{m i}^{t}$ & Water consumption to produce one unit raw material $\mathrm{m}$ from supplier $\mathrm{i}$ in \\
\hline$W O(M, F) T(D)_{j e}^{t}$ & $\begin{array}{l}\text { Fixed water consumption of opening (maintaining, closing) transformer } \\
\text { (distribution) site } j \text { using energy type e in period } t \text {; }\end{array}$ \\
\hline$W S I_{j}$ & Water stress index of site $\mathrm{j}$ \\
\hline$E O(M, F) T(D)_{j e}^{t}$ & $\begin{array}{l}\text { Fixed emission generated by opening (maintaining, closing) transformer } \\
\text { (distribution) site j using energy type e in period t; }\end{array}$ \\
\hline$E F C_{j}$ & Efficiency score of site $\mathrm{j}$ \\
\hline $\mathrm{a}, \mathrm{b}, \mathrm{c}$ & Weights of co2 emission, water consumption and created job, respectively. \\
\hline
\end{tabular}

The following decision variables are used in the model: 


\begin{tabular}{l|l}
\hline$s(o, f) t(d)_{j}^{t}$ & $\begin{array}{l}\text { Binary variable indicating the current state (opening, closing) of transformer } \\
\text { (distributor) site } \mathrm{j} \text { in period } \mathrm{t} \text { (open }=1 \text {, close }=0 \text { ); }\end{array}$ \\
\hline$q i(m, f) t(d)_{j}^{t}$ & $\begin{array}{l}\text { Integer variable indicating the increased (available, decreased) capacity of } \\
\text { transformer (distributor) site } \mathrm{j} \text { in period t; }\end{array}$ \\
\hline$a s(t, d) t(d, c)_{m i j s}^{t}$ & $\begin{array}{l}\text { Amount of raw material/component/product } \mathrm{m} \text { transported from supplier } \\
\text { (transformer, distributor) } \mathrm{i} \text { to transformer (distributor, client) } \mathrm{j} \text { using } \\
\text { transportation method s in period t; }\end{array}$ \\
\hline$a p p(m)_{p j e}^{t}$ & $\begin{array}{l}\text { Amount of product (component) } \mathrm{p} \text { manufactured in transformer site } \mathrm{j} \text { using } \\
\text { energy type e in period t. }\end{array}$ \\
\hline
\end{tabular}

In this model, client' demands are given in advance. The potential supplier, transformer and distributor locations as well as their capacities are also known. For each selected actor, a decision must be made on the total units of raw materials that need to be purchased and transported from the selected supplier, the total units of products that need to be produced by the transformer and transported to the distributor, and the total units of products that need to be distributed from the distributor to the client.

The total cost of the supply chain includes purchasing raw materials costs, production costs, distribution costs, transportation costs, fixed opening and closing costs, site maintaining costs, and site capacity change costs. On the other hand, we also assume that the carbon emissions and water consumption come from three sources as follows:

i. From suppliers: the production of raw materials and the its transportation to the transformers;

ii. From transformers: maintaining the sites, the production of the products, and the transportation of the products to the distributors ;

iii. From distributors: maintaining the sites and delivering the products to the client. Finally, the amount to created jobs is associated with the opening and closing of the sites.

Three objective functions are shown in equation 8 to equation 10. Objective function $1(\mathrm{Obj} 1)$ as shown in equation 8 represents minimizing the objective function associated with economic dimension of sustainability mentioned in Table 2. It is respectively the summation of transportation costs: (1) from distributors to costumers, (2) from transformers and distributors (3) from transformers to transformers and (4) from suppliers to transformers, fixed costs of (opening, maintaining, and closing) transformer sites and distributor sites, fixed costs of increasing (maintaining, decreasing) capacity of transformer sites and distributor sites, supplying costs, production costs and distribution costs respectively. 


$$
\begin{aligned}
& \text { Obj1 }=\min \left(\sum_{s \in S} \sum_{t \in T} \sum_{p \in P} \sum_{k \in K} \sum_{l \in L} C D C_{p k l s}^{t} a d c_{p k l s}^{t}+\sum_{s \in S} \sum_{t \in T} \sum_{p \in P} \sum_{j \in J} \sum_{k \in K} C T D_{p j k s}^{t} a t d_{p j k s}^{t}\right. \\
& \left.+\sum_{s \in S} \sum_{t \in T} \sum_{m \in M} \sum_{j \in J} \sum_{j \in J \supset J} C T T_{m j j j^{t}}^{t} a t t_{m j j j^{\prime}}^{t}+\sum_{s \in S} \sum_{t \in T} \sum_{m \in M} \sum_{i \in I} \sum_{j \in J} C S T_{m i j s}^{t} a s t_{m i j s}^{t}\right) \\
& +\left(\sum_{e \in E} \sum_{t \in T} \sum_{j \in J}\left(C O T_{j e}^{t} o t_{j e}^{t}+C M T_{j}^{t} s t_{j}^{t}+C F T_{j e}^{t} f t_{j e}^{t}\right)+\sum_{e \in E} \sum_{t \in T} \sum_{k \in K}\left(C O D_{k e}^{t} o d_{k e}^{t}+C M D_{k}^{t} s d_{k}^{t}+C F D_{k e}^{t} f d_{k e}^{t}\right)\right) \\
& +\left(\sum_{t \in T} \sum_{j \in J}\left(C I C T_{j}^{t} q i t_{j}^{t}+C M C T_{j}^{t} q m t_{j}^{t}+C F C T_{j}^{t} q f t_{j}^{t}\right)+\sum_{t \in T} \sum_{k \in K}\left(C I C D_{k}^{t} q i d_{k}^{t}+C M C D_{k}^{t} q m d_{k}^{t}+C F C D_{k}^{t} q f d_{k}^{t}\right)\right) \\
& +\left(\sum_{e \in E} \sum_{t \in T} \sum_{p \in P} \sum_{j \in J} C P P_{p j e}^{t} a p p_{p j e}^{t}+\sum_{e \in E} \sum_{t \in T} \sum_{m \in M} \sum_{j \in J} C P M_{m j e}^{t} a p m_{m j e}^{t}\right)+\sum_{t \in T} \sum_{m \in M} \sum_{i \in I} \sum_{j \in J} C S M_{m i}^{t} a s t_{m i j}^{t}
\end{aligned}
$$

Objective function $2(\mathrm{Obj} 2)$ as shown in equation 9 represents minimizing the sum of environmental and social objective functions. The environmental function is the sum of total $\mathrm{CO}_{2}$ emissions and total water consumed. Total $\mathrm{CO}_{2}$ emissions is respectively the sum of (1) fixed $\mathrm{CO}_{2}$ emissions generated when opening, closing and maintaining transformer and distributor sites and (2) variable $\mathrm{CO}_{2}$ emissions generated by transportation: (i) from distributors to costumers, (ii) from transformers to distributors, (iii) from transformers to transformers and (iv) from suppliers to transformers, the total emissions by energy mode at transformer sites and the total emissions of producing raw materials from suppliers. Total consumed water is respectively the sum of fixed consumed water when maintaining, closing and opening transformer and distributor sites and variable consumed water from suppliers, transformers and distributors. The social function is the number of jobs created or destructed when opening or closing transformer and distributor sites. The three functions total $\mathrm{CO}_{2}$ emissions, total water consumption and the number of created or destructed jobs are weighted by factors $a, b$ and $c$. 


$$
\begin{aligned}
\text { Obj2 }=\min \mathrm{a}\left(\sum_{s \in S}\right. & \sum_{t \in T} \sum_{p \in P} \sum_{k \in K} \sum_{l \in L} E D C_{p k l s}^{t} a d c_{p k l s}^{t}+\sum_{s \in S} \sum_{t \in T} \sum_{p \in P} \sum_{j \in J} \sum_{k \in K} E T D_{p j k s}^{t} a t d_{p j k s}^{t} \\
& +\sum_{s \in S} \sum_{t \in T} \sum_{m \in M} \sum_{j \in J} \sum_{j^{\prime} \in J \not j} E T T_{m j j^{\prime} s}^{t} a t t_{m j j^{\prime} s}^{t}+\sum_{s \in S} \sum_{t \in T} \sum_{m \in M} \sum_{i \in I} \sum_{j \in J} E S T_{m i j s}^{t} a s t_{m i j s}^{t} \\
& +\sum_{e \in E} \sum_{t \in T} \sum_{j \in J}\left(E O T_{j e}^{t} o t_{j e}^{t}+E M T_{j}^{t} s t_{j}^{t}+E F T_{j e}^{t} f t_{j e}^{t}\right) \\
& +\sum_{e \in E} \sum_{t \in T} \sum_{k \in K}\left(E O D_{k e}^{t} o d_{k e}^{t}+E M D_{k}^{t} s d_{k}^{t}+E F D_{k e}^{t} f d_{k e}^{t}\right)+\sum_{e \in E} \sum_{t \in T} \sum_{p \in P} \sum_{j \in J} E P P_{p j e}^{t} a p p_{p j e}^{t} \\
& \left.+\sum_{e \in E} \sum_{t \in T} \sum_{m \in M} \sum_{j \in J} E P M_{m j e}^{t} a p m_{m j e}^{t}+\sum_{t \in T} \sum_{m \in M} \sum_{i \in I} \sum_{j \in J} E P R_{m i}^{t} a s t_{m i j}^{t}\right) \\
& +b\left(\sum_{e \in E} \sum_{t \in T} \sum_{p \in P} \sum_{j \in J} W S I_{j} W P P_{p j e}^{t} a p p_{p j e}^{t}+\sum_{e \in E} \sum_{t \in T} \sum_{m \in M} \sum_{j \in J} W S I_{j} W P M_{m j e}^{t} a p m_{m j e}^{t}\right. \\
& +\sum_{e \in E} \sum_{t \in T} \sum_{j \in J} W S I_{j}\left(W O T_{j e}^{t} o t_{j e}^{t}+W M T_{j}^{t} s t_{j}^{t}+W F T_{j e}^{t} f t_{j e}^{t}\right) \\
& +\sum_{e \in E} \sum_{t \in T} \sum_{k \in K} W S I_{k}\left(W O D_{k e}^{t} o d_{k e}^{t}+W M D_{k}^{t} S d_{k}^{t}+W F D_{k e}^{t} f d_{k e}^{t}\right) \\
& \left.+\sum_{t \in T} \sum_{m \in M} \sum_{i \in I} \sum_{j \in J} W S I_{i} W P R_{m i}^{t} a s t_{m i j}^{t}\right)-c\left(\sum_{e \in E} \sum_{t \in T} \sum_{j \in J}\left(J C_{j}^{t} o t_{j e}^{t}-J C_{j}^{t} f t_{j e}^{t}\right)\right. \\
& \left.+\sum_{e \in E} \sum_{t \in T} \sum_{k \in K}\left(J C_{k}^{t} o d_{k e}^{t}-J C_{k}^{t} f d_{k e}^{t}\right)\right)
\end{aligned}
$$

The third objective function is to maximize the total efficiency of the supply chain using calculated efficiency (from Stage I of the proposed two stage approach) for each site respectively transformers, distributors and suppliers.

$$
\begin{aligned}
\text { Obj3 }=\max \sum_{e \in E} \sum_{t \in T} \sum_{j \in J} E F C_{j}\left(o t_{j e}^{t}+s t_{j}^{t}\right)+\sum_{e \in E} \sum_{t \in T} \sum_{k \in K} E F C_{k}\left(o d_{k e}^{t}+s d_{k}^{t}\right)+\sum_{t \in T} \sum_{s \in I} E F C_{s} s e_{s}^{t} \\
\text { with } s e_{s}^{t}=1 \text { if } \sum_{m \in M} \sum_{i \in I} \sum_{j \in J} a s t_{m i j s}^{t}>0, \text { else se } e_{s}^{t}=0
\end{aligned}
$$

Subject to the following constraints:

1. All orders of the clients should be satisfied.

$$
\sum_{s \in S} \sum_{k \in K} a d c_{p k l s}^{t}=D_{p l}^{t}(t \in T, p \in P, l \in L)
$$

2. The amount of raw material supplied from a supplier cannot exceed its capacity.

$$
\sum_{s \in S} \sum_{j \in J} a s t_{m i j s}^{t}=Q S_{m i}^{t}(t \in T, m \in M, i \in I)
$$

3. Capacity restrictions of transformer sites and distribution sites.

Constraints (13) and (14) indicate relation between available, increasing and decreasing capacity of a transform site

$$
q m t_{j}^{1}=Q I C T_{j}+q i t{ }_{j}^{1}-q f t{ }_{j}^{1}(j \in J)
$$




$$
q m t_{j}^{t}=q m t_{j}^{t-1}+q i t_{j}^{t}-q f t_{j}^{t}(j \in J, t \geq 2)
$$

Constraint (15) indicate respecting capacity constraints (Upper Bound and Lower Bound) of a tr ansformer site and constraint (16) indicate that the produced quantities could not exceed the available capacity at a transformer site

$$
\begin{gathered}
Q L T_{j} s t_{j}^{t} \leq q m t_{j}^{t} \leq Q U T_{j} s t_{j}^{t}(j \in J, t \in T) \\
\sum_{e \in E} \sum_{m \in M} a p m_{m j e}^{t}+\sum_{e \in E} \sum_{p \in P} a p p_{p j e}^{t} \leq q m t_{j}^{t}(j \in J, t \in T)
\end{gathered}
$$

Constraints (17) and (18) indicate relation between available, increasing and decreasing capacity of a distributor site

$$
\begin{gathered}
q m d_{k}^{1}=Q I C D_{k}+q i d_{k}^{1}-q f d_{k}^{1}(k \in K) \\
q m d_{k}^{t}=q m d_{k}^{t-1}+q i d_{k}^{t}-q f d_{k}^{t}(k \in K, t \geq 2)
\end{gathered}
$$

Constraint (19) indicate respecting capacity constraints (Upper Bound and Lower Bound) of a distributor site and constraint (20) indicate that the delivered quantities could not exceed the available capacity at a distributor site

$$
\begin{gathered}
Q L D_{k} s d_{k}^{t} \leq q m d_{k}^{t} \leq Q U D_{k} s d_{k}^{t}(k \in K, t \in T) \\
\sum_{s \in S} \sum_{p \in P} \sum_{l \in L} a d c_{p k l s}^{t} \leq q m d_{k}^{t}(k \in K, t \in T) \\
\sum_{s \in S} \sum_{j \in J} a t d_{p j k s}^{t}=\sum_{s \in S} \sum_{l \in L} a d c_{p k l s}^{t}(k \in K, t \in T, p \in P)
\end{gathered}
$$

4. Capacity constraints of transforming raw materials or components to products.

$$
\begin{aligned}
\sum_{e \in E} a p m_{m j e}^{t}+ & \sum_{s \in S} \sum_{i \in I} a s t_{m i j s}^{t}+\sum_{s \in S} \sum_{j^{\prime} \in J \not j} a t t_{m j^{\prime} j s}^{t} \\
& \geq \sum_{s \in S} \sum_{j^{\prime} \in J \not j} a t t_{m j j^{\prime} s}^{t}+\sum_{m^{\prime} \in M \not \supset m} B O M_{m m^{\prime}} \sum_{e \in E} a p m_{m^{\prime} j e}^{t} \\
& +\sum_{p \in P} B O M_{m p} \sum_{e \in E} a p p_{p j e}^{t}
\end{aligned}
$$




$$
\sum_{e \in E} a p p_{p j e}^{t}=\sum_{s \in S} \sum_{k \in K} a t d_{p j k s}^{t}(j \in J, t \in T, p \in P)
$$

5. Sites' opening and closing constraints where $M$ is a very large constant.

$$
\begin{gathered}
M \times s t_{j}^{t}-\left(\sum_{e \in E} \sum_{m \in M} a p m_{m j e}^{t}+\sum_{e \in E} \sum_{p \in P} a p p_{p j e}^{t}\right) \geq 0(t \in T, j \in J) \\
M \times s t_{j}^{t}-\sum_{s \in S} \sum_{m \in M} \sum_{i \in I} a s t_{m i j s}^{t} \geq 0(t \in T, j \in J) \\
M \times s t_{j}^{t}-\sum_{s \in S} \sum_{m \in M} \sum_{j^{\prime} \in J \not j} a t t_{m j^{\prime} j s}^{t} \geq 0(t \in T, j \in J) \\
M \times s t_{j}^{t}-\sum_{s \in S} \sum_{p \in P} \sum_{k \in K} a t d_{p j k s}^{t} \geq 0(t \in T, j \in J) \\
M \times s d_{k}^{t}-\sum_{s \in S} \sum_{p \in P} \sum_{j \in J} a t d_{p j k s}^{t} \geq 0(t \in T, k \in K) \\
M \times s d_{k}^{t}-\sum_{s \in S} \sum_{p \in P} \sum_{l \in L} a d c_{p k l s}^{t} \geq 0(t \in T, k \in K)
\end{gathered}
$$

6. Sites' opening and closing continuity constraints.

$$
\begin{array}{r}
s t_{j}^{t}+\sum_{e \in E} f t_{j e}^{t} \leq 1(t \in T, j \in J) \\
s t_{j}^{t}-\sum_{e \in E} o t_{j e}^{t} \geq 0(t \in T, j \in J) \\
s d_{k}^{t}+\sum_{e \in E} f d_{k e}^{t} \leq 1(t \in T, k \in K) \\
s d_{k}^{t}-\sum_{e \in E} o d_{k e}^{t} \geq 0(t \in T, k \in K) \\
s t_{j}^{1} \leq I O T_{j}+\sum_{e \in E} o t_{j e}^{1} \leq 1(j \in J) \\
s t_{j}^{t} \leq s t_{j}^{t-1}+\sum_{e \in E} o t_{j e}^{t} \leq 1(t \geq 2, j \in J) \\
s d_{k}^{1} \leq I O D_{k}+\sum_{e \in E} o d_{k e}^{1} \leq 1(k \in K) \\
s d_{k}^{t} \leq s d_{k}^{t-1}+\sum_{e \in E} o d_{k e}^{t} \leq 1(t \geq 2, k \in K) \\
1-s t_{j}^{1} \leq\left(1-I O T_{j}\right)+\sum_{e \in E} f t_{j e}^{1} \leq 1(j \in J) \\
1-s t_{j}^{t} \leq\left(1-s t_{j}^{t-1}\right)+\sum_{e \in E} f t_{j e}^{t} \leq 1(t \geq 2, j \in J) \\
1-s d_{k}^{1} \leq\left(1-I O D_{k}\right)+\sum_{e \in E} f d_{k e}^{1} \leq 1(k \in K) \\
1-s d_{k}^{t} \leq\left(1-s d_{k}^{t-1}\right)+\sum_{e \in E} f d_{k e}^{t} \leq 1(t \geq 2, k \in K)
\end{array}
$$

7. Positivity, integrality and binary constraints. 


$$
\begin{aligned}
& s t_{j}^{t}, o t_{j e}^{t}, f t_{j e}^{t} \in\{0,1\}(t \in T, j \in J, e \in E) \\
& s d_{k}^{t}, o d_{k e}^{t}, f d_{k e}^{t} \in\{0,1\}(t \in T, k \in K, e \in E) \\
& \mathrm{qit}_{\mathrm{j}}^{\mathrm{t}}, \mathrm{qmt}_{\mathrm{j}}^{\mathrm{t}}, \mathrm{qft}_{\mathrm{j}}^{\mathrm{t}} \geq 0 \text { and are integers }(\mathrm{t} \in \mathrm{T}, \mathrm{j} \in \mathrm{J}) \\
& \operatorname{qid}_{\mathrm{k}}^{\mathrm{t}}, \mathrm{qmd}_{\mathrm{k}}^{\mathrm{t}}, \mathrm{qfd}_{\mathrm{k}}^{\mathrm{t}} \geq 0 \text { and are integers }(\mathrm{t} \in \mathrm{T}, \mathrm{k} \in \mathrm{K}) \\
& \operatorname{ast}_{\text {mijs }}^{\mathrm{t}} \geq 0 \text { and is integer }(\mathrm{t} \in \mathrm{T}, \mathrm{i} \in \mathrm{I}, \mathrm{j} \in \mathrm{J}, \mathrm{m} \in \mathrm{M}, \mathrm{s} \in \mathrm{S} \text { ) } \\
& \operatorname{att}_{\mathrm{mj}^{\prime} j \mathrm{js}}^{\mathrm{t}} \geq 0 \text { and is integer }\left(\mathrm{t} \in \mathrm{T}, \mathrm{j} \in \mathrm{J}, \mathrm{j}^{\prime} \in \mathrm{J} \not \supset \mathrm{j}, \mathrm{m} \in \mathrm{M}, \mathrm{s} \in \mathrm{S}\right) \\
& \operatorname{atd}_{\mathrm{pjks}}^{\mathrm{t}} \geq 0 \text { and is integer }(\mathrm{t} \in \mathrm{T}, \mathrm{j} \in \mathrm{J}, \mathrm{k} \in \mathrm{K}, \mathrm{p} \in \mathrm{P}, \mathrm{s} \in \mathrm{S} \text { ) } \\
& \operatorname{adc}_{\text {pkls }}^{\mathrm{t}} \geq 0 \text { and is integer }(\mathrm{t} \in \mathrm{T}, \mathrm{k} \in \mathrm{K}, \mathrm{l} \in \mathrm{L}, \mathrm{p} \in \mathrm{P}, \mathrm{s} \in \mathrm{S} \text { ) } \\
& \operatorname{apm}_{m j e}^{t} \geq 0 \text { and is integer }(t \in T, j \in J, m \in M, e \in E) \\
& a p p_{p j e}^{t} \geq 0 \text { and is integer }(t \in T, j \in J, p \in P, e \in E)
\end{aligned}
$$

\subsubsection{Solution methodology}

Clearly, generating all the alternatives and comparing them would be prohibitive in terms of time and resources. The main difficulties associated with the creation of the Pareto set are solving the multi-objective optimization problem in which several criteria must be simultaneously minimized, and a sufficiently large number of solutions should be generated, identified and filtered. In practice, the visualization and analysis of the Pareto set becomes highly difficult in problems with more than three objectives. Therefore, in this paper, the environmental and social aspects are merged into one objective to reduce the complexity and make it practical. Next, a method is proposed to generate a Pareto front. The structure of this method is shown in Figure 6. The main idea of this approach is to use an LP solver to generate the Pareto set. First, we take into consideration only the first objective function, and use LP solver to obtain an optimum solution, whose value is considered the lower bound $\mathrm{LB}_{\text {eco }}$ of first objective function.

Then, we use equation (52) as a constraint, while taking into consideration the second objective function only.

$$
\text { Objective function } 1=L B_{\text {eco }}
$$

In this way, the second objective can be optimized without sacrificing the first objective. Thus, we can obtain a solution $T_{\text {eco }}$ whose value is considered as the upper bound $\mathrm{UB}_{\text {env }}$ of the second 
objective function. Finally, we calculate the value $\mathrm{V}_{\text {eff }}$ of the third objective function. So that's the solution $\mathrm{T}_{\text {eco }}$ with the objective values $\left(\mathrm{LB}_{\text {eco }}, \mathrm{UB}_{\text {env }}, \mathrm{V}_{\mathrm{eco}}\right)$ is a bound point of the Pareto front.

In the same manner, we repeat this procedure but switching the order of considering the two objectives. We are able to get the lower bound $\mathrm{LB}_{\text {env }}$ of the second objective function and the upper bound $\mathrm{UB}_{\text {eco }}$ of the first objective function, as well as a second bound point solution $\mathrm{T}_{\text {env }}$ with the objective values ( $\left.\mathrm{UB}_{\text {eco }}, \mathrm{LB}_{\text {env }}, \mathrm{V}_{\text {env }}\right)$.

In the next step, we calculate the difference $\mathrm{D}_{\text {eco }}$ between the $\mathrm{LB}_{\text {eco }}$ and $\mathrm{UB}_{\text {eco }}$, and use equation (53) as a constraint where we relax the $L B_{\text {eco }}$ by a certain percentage. For each $n=1 \ldots 9$, we optimize the second objective function, thus we are able to obtain a set $S_{\text {env }}$ of 9 solutions.

$$
\text { Objective function } 1 \leq L B_{\text {eco }}+10 \% \times n \times D_{\text {eco }}(n=1 \ldots 9)
$$

Following the same approach, we calculate the difference $\mathrm{D}_{\text {env }}$ between the $\mathrm{LB}_{\text {env }}$ and $\mathrm{UB}_{\text {env }}$, and use the equation (54) as a constraint where we relax the $\mathrm{LB}_{\text {env }}$ a certain percentage. For each $n=$ $1 \ldots 9$, we optimize the first objective function, thus we are able to obtain a set $S_{\text {eco }}$ of 9 solutions.

$$
\text { Objective function } 2 \leq L B_{\text {env }}+10 \% \times n \times D_{\text {env }}(n=1 \ldots 9)
$$

Finally, we merge the two sets $\mathrm{S}_{\text {env }}$ and $\mathrm{S}_{\mathrm{eco}}$, by eliminating the solutions dominated by other solutions. Thus, we obtain a new set of solutions $\mathrm{S}_{1}$ by putting together the result set and the two endpoints $\mathrm{T}_{\mathrm{eco}}$ and $\mathrm{T}_{\text {env }}$, as shown in Figure 7. Then, we repeat the whole procedure by considering objective 1 and objective 3, and obtain the second set of solutions $\mathrm{S}_{2}$. Then, again, we repeat the whole procedure by considering objective 2 and objective 3 , and obtain the third set of solutions $S_{3}$. Finally, we merge $S_{1}, S_{2}$ and $S_{3}$ to obtain the Pareto front. 


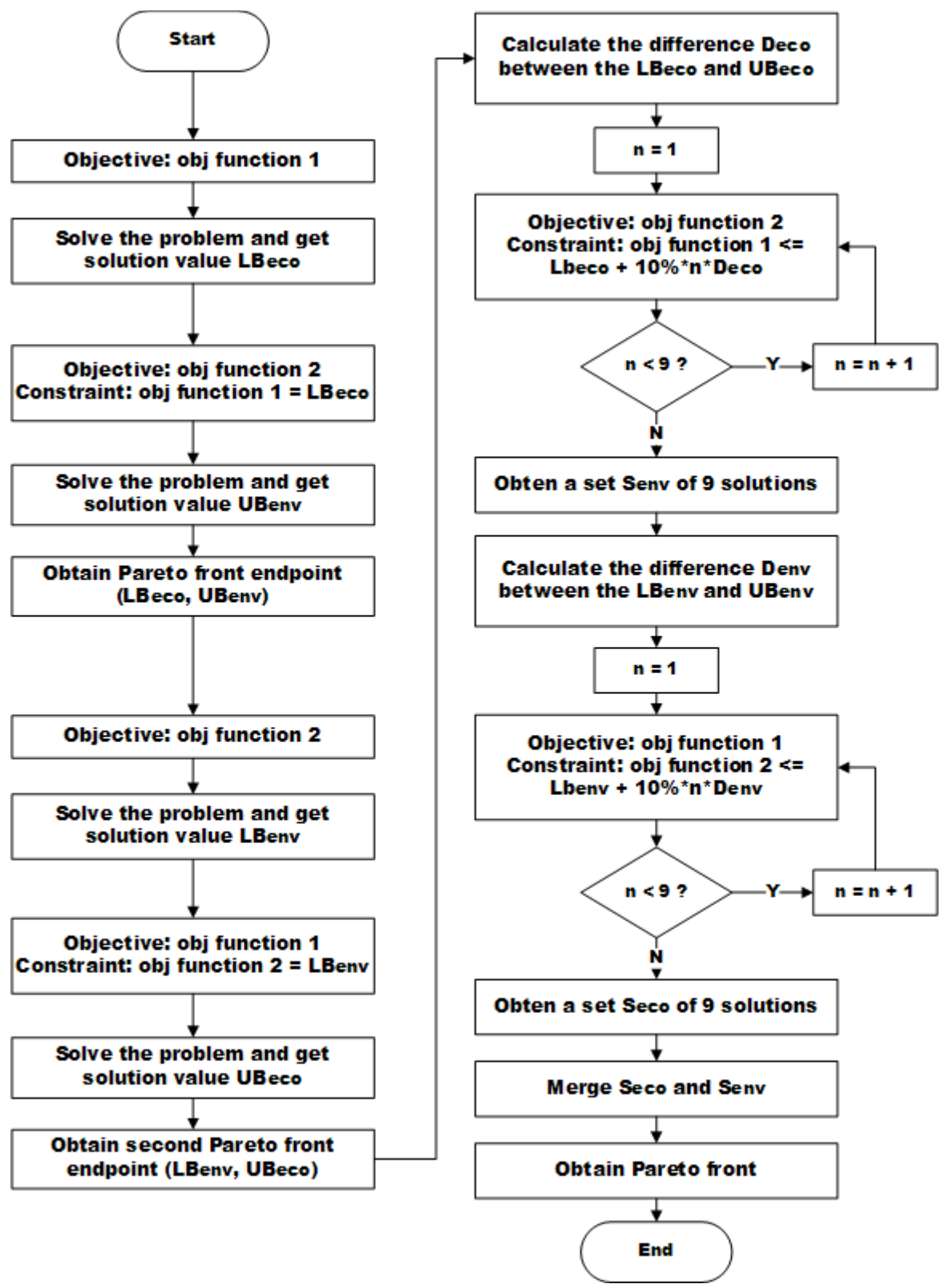

Figure 6: Structure of the Pareto front generating method 


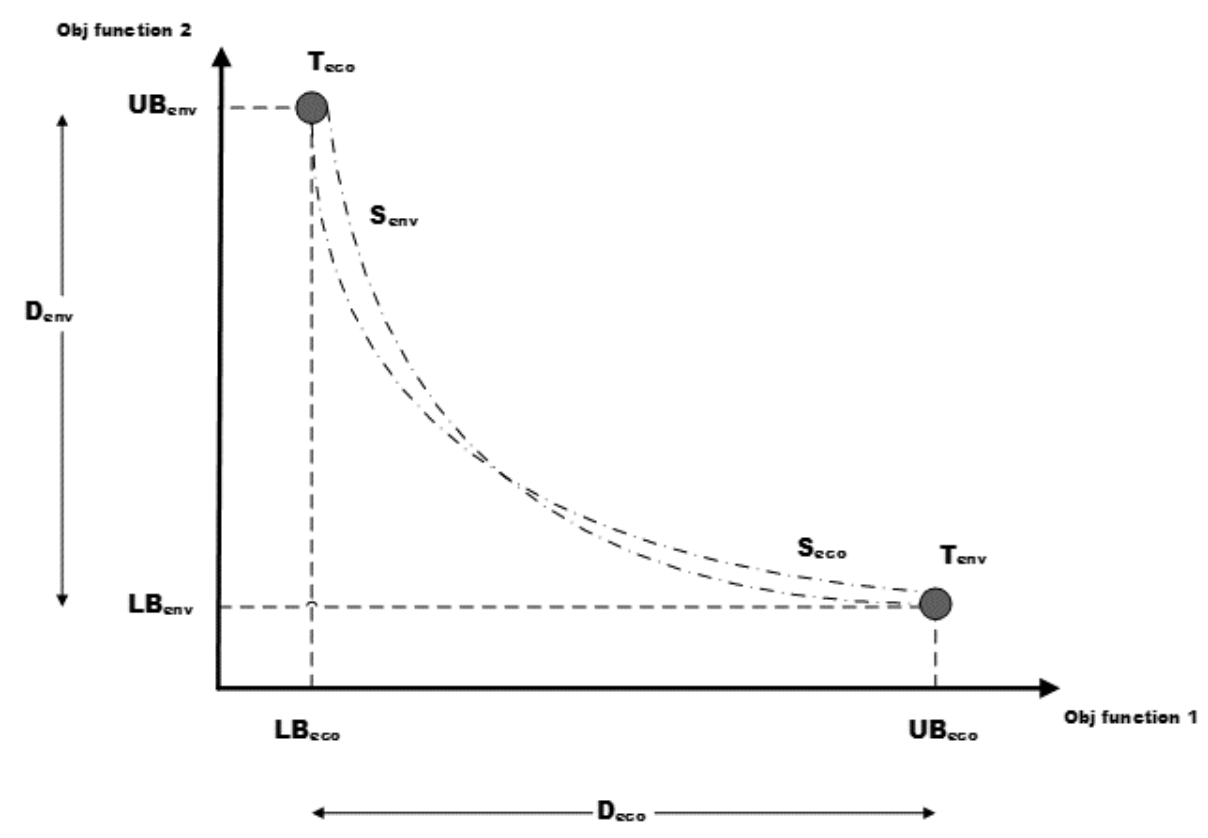

Figure 7: Pareto front constructed by our method

\section{A case study and results}

In order to provide a better understanding and to illustrate our approach, we apply our proposed methodology to a case study of an agro-food company. This case study aims to demonstrate the two-stage hybrid optimization approach, and illustrate the detailed calculation for each stage. We applied the proposed approach to design its new supply chain: it has 12 potential suppliers, three production sites, five distribution sites, and six clients. To simplify the case study, we consider only one product, one component, one energy mode, and one transportation mode. The company has to design its supply chain at minimal cost, while also considering the environmental and social impacts.

The first stage entails performing an initial evaluation of potential sites of an agro-food supply chain with a large number of criteria and sub-criteria in order to determine their efficiencies and effectiveness with respect to their performance in the agro-food supply chain. The criteria which may be too complex to integrate into an objective function in the second stage could be considered in the first stage. In doing so, we are able to evaluate each alternative separately in order to rank them and to choose the more competitive sites. The evaluation is performed by using the Analytic Hierarchy Process (AHP) method mentioned in section 3.1. The sites which record the best performance will be selected for the next stage. In this case study, since the 
amount of potential production and distribution sites is relatively small, we will only apply the first stage to the potential suppliers.

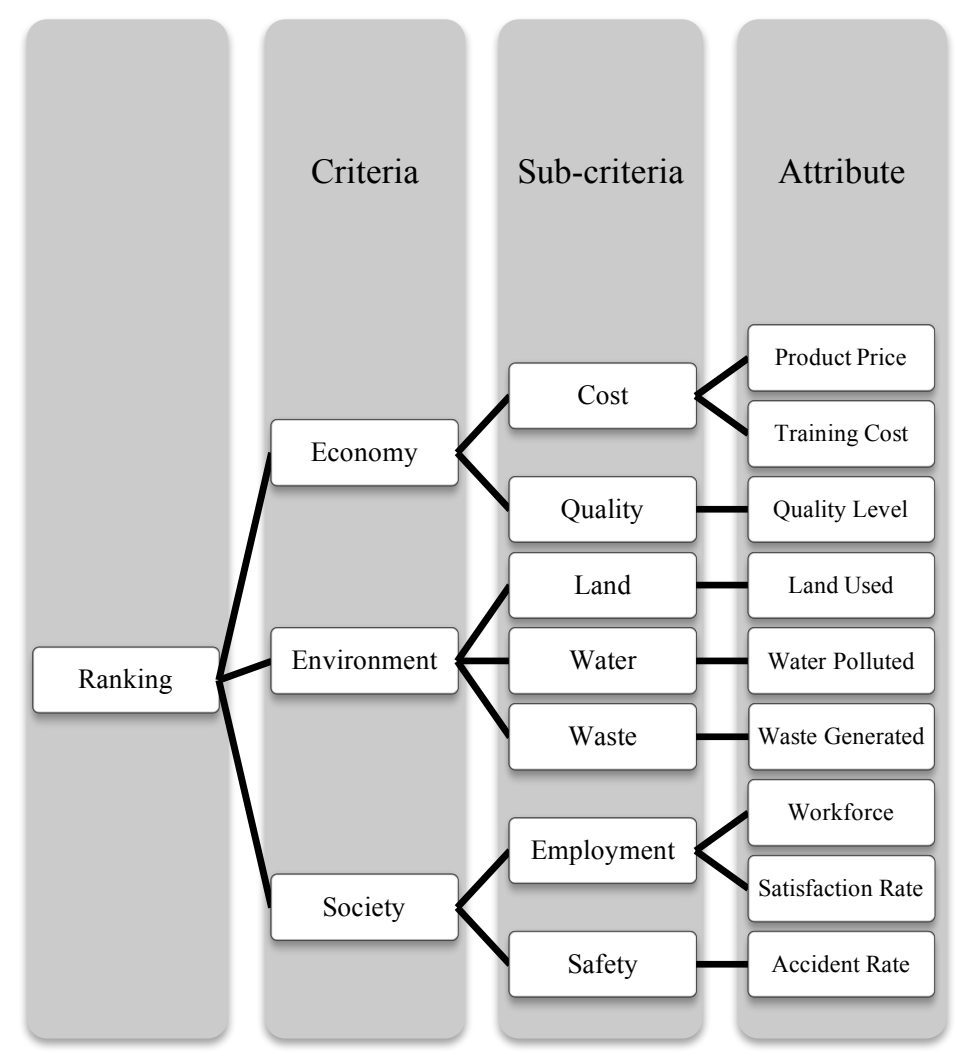

Figure 8: Stage 1 indicators used in this case study

Figure 8 shows an integral description of the different criteria, sub-criteria, and attributes considered in the first stage of this case study; however, there are more criteria (listed in Tables 3 and 4) that can be selected according to the user's preference.

Table 3 and Table 4 give the value of each attribute for each supplier. Similarly, this research considered the same approach for transformers and distributors; however, as the numbers of pages are limited, this research only highlights data related to suppliers. The following tables provide a set of data using a numerical scale. 


\begin{tabular}{c|c|c|c|c|c|c|c}
\hline Sub-criteria & Attributes & S1 & S2 & S3 & S4 & S5 & S6 \\
\hline \multirow{3}{*}{ Cost } & Product Price & 10 & 8 & 12 & 8 & 10 & 15 \\
\cline { 2 - 8 } & Training Cost & 20 & 15 & 10 & 25 & 15 & 10 \\
\hline Quality & Quality Level & 4 & 4 & 3 & 4 & 3 & 5 \\
\hline Land & Land Used & 1000 & 1200 & 800 & 1500 & 1100 & 600 \\
\hline Water & Water Polluted & 200 & 350 & 180 & 300 & 240 & 100 \\
\hline Waste & Waste Generated & 300 & 200 & 180 & 350 & 210 & 120 \\
\hline \multirow{2}{*}{ Employment } & Watisfaction Rate & 4 & 3 & 5 & 4 & 5 & 4 \\
\cline { 2 - 8 } & Accident Rate & 5 & 8 & 3 & 5 & 8 & 4 \\
\hline
\end{tabular}

Table 3: Data collected from the potential suppliers (part 1)

\begin{tabular}{c|c|c|c|c|c|c|c}
\hline Sub-criteria & Attributes & S7 & S8 & S9 & S10 & S11 & S12 \\
\hline \multirow{3}{*}{ Cost } & Product Price & 11 & 15 & 10 & 10 & 15 & 12 \\
\cline { 2 - 8 } & Training Cost & 18 & 20 & 5 & 15 & 12 & 5 \\
\hline \multirow{2}{*}{ Quality } & Quality Level & 3 & 3 & 4 & 3 & 3 & 4 \\
\hline Land & Land Used & 1400 & 1300 & 1000 & 1100 & 1500 & 800 \\
\hline Water & Water Polluted & 220 & 280 & 280 & 320 & 300 & 220 \\
\hline Waste & Waste Generated & 280 & 220 & 230 & 300 & 250 & 200 \\
\hline \multirow{2}{*}{ Employment } & Satisfaction Rate & 3 & 3 & 4 & 3 & 4 & 3 \\
\cline { 2 - 8 } & Accident Rate & 4 & 4 & 6 & 3 & 6 & 8 \\
\hline Safety & Workforce & 110 & 120 & 60 & 120 & 80 & \\
\hline
\end{tabular}

Table 4: Data collected from the potential suppliers (part 2)

The following step is used to calculate weights for the attributes of each sub-criterion. The weights are given according to the pairwise comparisons; a comparison result should be given to each two attributes by selecting a number from 1 to 9 or their reciprocals. The numbers $3,5,7$, 
and 9 correspond to the verbal judgments "moderately more dominant", "strongly more dominant", "very strongly more dominant", and "extremely dominant" (with 2, 4, 6, and 8 for compromise between the previous values). The results of this step are shown in Table 5.

\begin{tabular}{|c|c|c|c|c|c|c|c|c|c|}
\hline & $\begin{array}{l}\text { Product } \\
\text { Price }\end{array}$ & $\begin{array}{c}\text { Training } \\
\text { Cost }\end{array}$ & $\begin{array}{l}\text { Quality } \\
\text { Level }\end{array}$ & $\begin{array}{l}\text { Land } \\
\text { Used }\end{array}$ & $\begin{array}{l}\text { Water } \\
\text { Polluted }\end{array}$ & $\begin{array}{c}\text { Waste } \\
\text { Generated }\end{array}$ & Workforce & Satisfaction & Accident \\
\hline Product Price & 1 & 9 & 1 & 9 & 3 & 4 & 7 & 7 & 5 \\
\hline Training Cost & $1 / 9$ & 1 & $1 / 9$ & 1 & $1 / 3$ & $1 / 3$ & 1 & 1 & $1 / 2$ \\
\hline Quality Level & 1 & 9 & 1 & 9 & 3 & 4 & 7 & 7 & 5 \\
\hline Land Used & $1 / 9$ & 1 & $1 / 9$ & 1 & $1 / 3$ & $1 / 3$ & 1 & 1 & $1 / 2$ \\
\hline $\begin{array}{c}\text { Water } \\
\text { Polluted }\end{array}$ & $1 / 3$ & 3 & $1 / 3$ & 3 & 1 & 1 & 2 & 2 & 1 \\
\hline $\begin{array}{c}\text { Waste } \\
\text { Generated }\end{array}$ & $1 / 4$ & 3 & $1 / 4$ & 3 & 1 & 1 & 2 & 2 & 1 \\
\hline Workforce & $1 / 7$ & 1 & $1 / 7$ & 1 & $1 / 2$ & $1 / 2$ & 1 & 1 & $1 / 2$ \\
\hline Satisfaction & $1 / 7$ & 1 & $1 / 7$ & 1 & $1 / 2$ & $1 / 2$ & 1 & 1 & $1 / 3$ \\
\hline Accident & $1 / 5$ & 2 & $1 / 5$ & 2 & 1 & 1 & 2 & 3 & 1 \\
\hline
\end{tabular}

Table 5: Criteria pairwise comparison

Next, the weight of each attribute is calculated using AHP method and is shown in Table 6 . According to this table, the most important criteria are product price and quality. The training cost and the land used are the least important criteria considered.

\begin{tabular}{c|c}
\hline Attribute & Weight \\
\hline Product Price & 0.303 \\
\hline Training Cost & 0.034 \\
\hline Quality Level & 0.303 \\
\hline Land Used & 0.034 \\
\hline
\end{tabular}




\begin{tabular}{c|c}
\hline Water Polluted & 0.090 \\
\hline Waste Generated & 0.084 \\
\hline Workforce & 0.039 \\
\hline Satisfaction Rate & 0.039 \\
\hline Accident Rate & 0.073 \\
\hline
\end{tabular}

Table 6: Weights calculated by AHP method

\begin{tabular}{c|c|c|c|c|c|c}
\hline & S1 & S2 & S3 & S4 & S5 & S6 \\
\hline Total Score & 0.506 & 0.483 & 0.429 & 0.533 & 0.389 & 0.541 \\
& & & & & & \\
\hline Total Score & 0.385 & 0.289 & 0.436 & 0.388 & 0.213 & 0.388 \\
\hline
\end{tabular}

Table 7: Aggregated supplier ranking

The aggregated final scores are shown in Table 7. Potential supplier 6 has the highest score; therefore, it has the best overall performance. In this case study, we allow first $50 \%$ potential suppliers with better performances in comparison to others to enter to the second stage. These suppliers include: S6, S4, S1, S2, S9, and S3.

The second stage of this approach involves the application of mathematical model with 4 objective functions as discussed in section 3.2. The objectives represent respectively the cost, the emission, the water consumption, and the amount of jobs created. The general information for each site in the supply chain is shown as following in Table 8-11.

Table 8: Annual Order:

\begin{tabular}{c|c|c|c|c|c|c}
\hline Client & C1 & C2 & C3 & C4 & C5 & C6 \\
\hline Order & 30000 & 40000 & 20000 & 50000 & 30000 & 30000 \\
\hline
\end{tabular}


Table 9: Production Site data

\begin{tabular}{c|c|c|c}
\hline Site & P1 & P2 & P3 \\
\hline Production Capacity & 180000 & 170000 & 200000 \\
\hline Open/Close Cost & 120000 & 150000 & 200000 \\
\hline Status & Existing & Potential & Existing \\
\hline Production Cost & 15 & 20 & 5 \\
\hline Production Emission & 5 & 15 & 20 \\
\hline Water Consumption & 20 & 5 & 15 \\
\hline
\end{tabular}

Table 10: Distribution Site data

\begin{tabular}{l|l|l|l|l|l}
\hline Site & D1 & D2 & D3 & D4 & D5 \\
\hline Distribution Capacity & 30000 & 50000 & 30000 & 50000 & 100000 \\
\hline Open/Close Cost & 60000 & 100000 & 70000 & 80000 & 60000 \\
\hline Status & & & & & \\
\hline
\end{tabular}

Table 11: Supplier's capacity

\begin{tabular}{l|l|l|l|l|l|l}
\hline Supplier & S1 & S2 & S3 & S4 & S6 & S9 \\
\hline Capacity & 50000 & 50000 & 50000 & 60000 & 40000 & 50000 \\
\hline
\end{tabular}

The two dimensions selected for the Pareto frontier are: Cost and Emission. The frontier contains 10 solutions and each solution is generated using the CPLEX Optimization Tool. The detail of each solution is shown in Table 12. The frontier generated is illustrated in Figure 9. 


\begin{tabular}{c|c|c|c|c|c|c|c|c|c|c}
\hline ID & 1 & 2 & 3 & 4 & 5 & 6 & 7 & 8 & 9 & 10 \\
\hline Cost & 1754939 & 1823941 & 1986217 & 1986217 & 3346974 & 4606785 & 4606785 & 4606785 & 4958769 & 5158769 \\
\hline Emission & 5834452 & 5616732 & 5216217 & 5216217 & 3156974 & 1776785 & 1776785 & 1776785 & 1698769 & 1698769 \\
\hline Water & 34000 & 32000 & 30000 & 30000 & 350000 & 390000 & 390000 & 390000 & 362000 & 362000 \\
\hline Job & 460 & 460 & 460 & 460 & 640 & 640 & 640 & 640 & 610 & 810 \\
\hline
\end{tabular}

Table 12: Data for the Pareto frontier

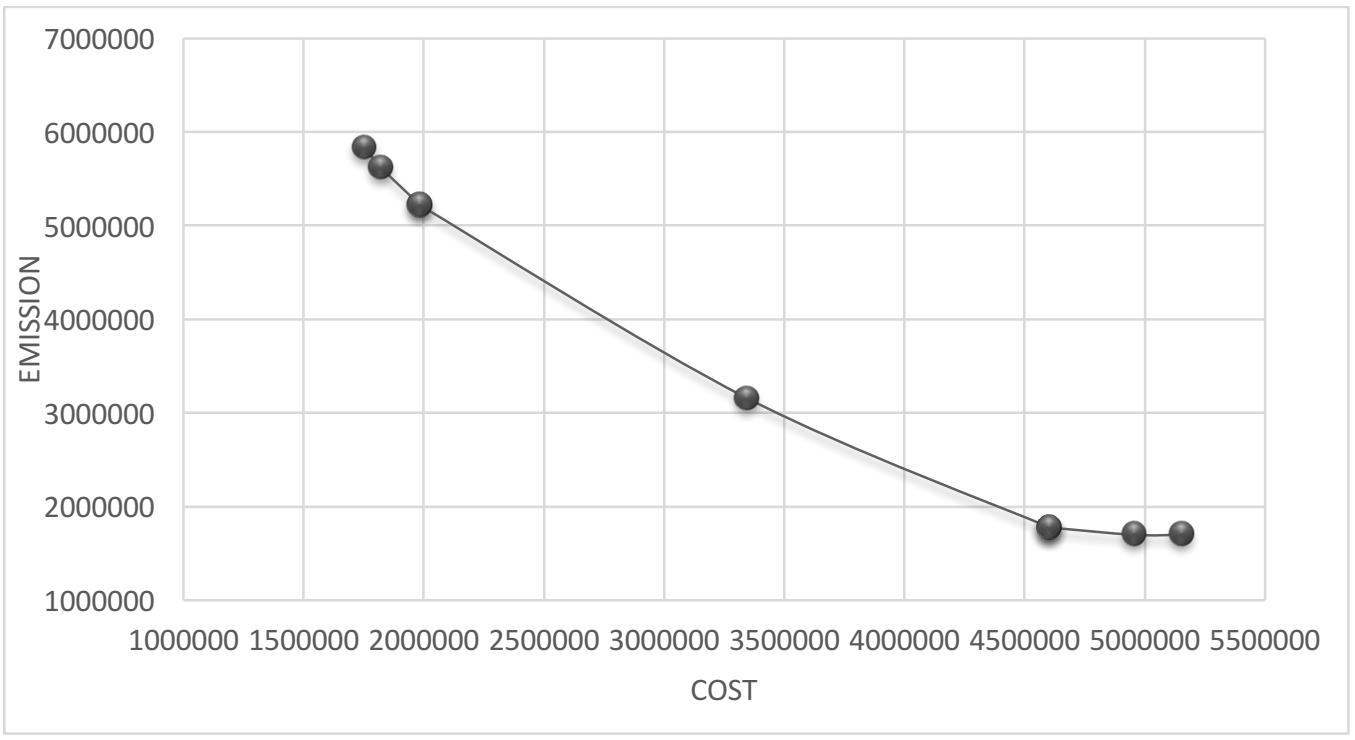

Figure 9: Pareto frontier

It is obvious that the supply chain design changes when we focus on different objectives. For example, in solution 1 , we are able to minimize the cost to 1754939 ; however, the emission in this case is increased to 5834452. Similarly, for solution 10 , we can minimize the emission to 1698769 whereas the cost is increased to 5158769 . The most balanced solution is solution No. 4 , which optimizes the cost to 3346974 units and decreases the emission to 3156974 units. The results of this case study demonstrates that our approach can not only adopt the supply chain network design strategy according to the different objectives but also consider the trade-off effect to avoid selecting inefficient partners and improve the efficiency of the optimization process.

The decision maker can select the most preferred solution from the solution set according to the need of the company, or apply different supply chain design criteria at different stages of the 
development of the company. The results of this study show also that the approach can be a useful for managers seeking to redesign agro-food supply chain while considering various performance criteria of sustainability. A balance between environmental emission and cost could be achieved based on establishing a tradeoff using this model.

The classical problem of network design optimization in supply chains is known to be NP-hard. Since the problem studied in this paper is more general, it's also NP-hard. To give an idea on the computational time of the second stage of the proposed approach based on the MILP model, we generated four instances with different number of suppliers, transformers, distributers and retailers in the case of only one product and one objective function (cost). For each instance we generated six random set of data (unit-costs, demand,...). For each instance we performed the six executions of the MILP and we calculated the average of computational time in seconds (see Table 13):

\begin{tabular}{|c|c|c|c|c|}
\hline $\begin{array}{c}\mathrm{Nb} \\
\text { Suppliers }\end{array}$ & $\begin{array}{c}\mathrm{Nb} \\
\text { Transformers }\end{array}$ & $\begin{array}{c}\mathrm{Nb} \\
\text { Distributors }\end{array}$ & $\begin{array}{c}\mathrm{Nb} \\
\text { Retailers }\end{array}$ & $\begin{array}{c}\text { Average Cplex Run } \\
\text { Time (S) }\end{array}$ \\
\hline 10 & 5 & 5 & 10 & 0.36 \\
\hline 20 & 10 & 10 & 20 & 35.27 \\
\hline 40 & 20 & 20 & 40 & 383.78 \\
\hline 80 & 40 & 40 & 80 & 3525.86 \\
\hline
\end{tabular}

Table 13: Computational Time of MILP model

As we can see that the run time increases considerably with increasing size of instances. The run time of the last instance is near to one hour for only one objective function and one product. The computational time increases also with increasing number of objective functions and with taking into account all aspects of sustainability addressed in this paper. Therefore the computational time could become exorbitant. In this case one could use the first stage to limit number of sites to consider in the second stage. Otherwise using heuristics or meta-heuristics could be justified which is one of our perspectives.

Overall, the proposed two-stage hybrid method helps to model a complex sustainable agro-food supply chain design problem and simplify the solution method using a simple multi criteria decision-making and multi objective optimization model. The use of AHP and OWA in first step helps to advance the reliability of the solution and adjust if necessary. In the second step, an integer linear programming based multi-objective optimization model helps to improve the efficiency of the approach. Overall, these two steps integrated together help to provide an efficient solution methodology and provide results to solve a complex problem. The proposed approach is efficient since it helps to take into account the various sustainability criteria in the 
first stage and judgments of decisions makers to establish the weight of each criterion. The first stage calculates an efficiency score of each partner (suppliers, transformers and distributors). This score helps to keep only the good candidates to be considered in the second stage of calculation. Since we use an MILP in the second stage, if the computational time of the algorithm is exorbitant then the list of potential list of partners established in the first stage could be reduced to provide an efficient solution.

\section{Conclusion and Discussion}

Given the increased concern over sustainability of supply chains, the need to develop decision support tools for the evaluation and optimization of multiple criteria and multi-objective problems in the agro-food supply chain is evident. Despite the growing interest in optimal network design of sustainable supply chains in operational research, effective approaches allowing the implementation of the three pillars (economy, environment, and society) are scarce. This research proposed an integrated two-stage hybrid approach for sustainable agro-food supply-chain network design. This method allowed the connection of sustainability criteria to the supply chain network design decisions in agro-food supply chains. In stage one of the decision-making process, a multicriteria decision-making model based on integrated AHP and OWA operators is used. This stage allows the decision makers to evaluate separately each alternative according to several criteria and sub-criteria associated with three dimensions of sustainability, in order to rank and subsequently make a selection. Consequently, this stage has a practical meaning in aggregating supply chain performance and assessing the supply chain partners. The very nature of the AHP and OWA procedures gives rise to their combination and creates a more powerful decisionmaking tool. In stage two, a multi-objective mathematical model, encompassing all three dimensions of sustainability, is formulated to design the agro-food supply chain network and to identify the optimal decisions. A simple but efficient method based on the linear programming model is used to generate the Pareto front of the mathematical model. To illustrate our approach, we presented and solved a case study of an agro-food company. We also illustrated how this twostep process can be used by a decision maker as a decision support tool to assist them in choosing the supply chain design decision that best suits their preferences in terms of economic, environmental, and social performances.

In our future work, we intend to deepen our research on operational research decision-making tools by integrating sustainability concerns for the agro-food industry, where sustainable development is of paramount importance. For the first stage, we may consider using other advanced multi-criteria decision-making approaches. A comparative analysis of the proposed 
methodology to other MCDM and MOOM will still be needed. For the second stage we would like to use meta-heuristics to solve the mathematical model, in order to further improve the efficiency of the approach in terms of computational time. We intend also to use a similar concept for multi-criteria decision-making problems in sustainable freight transportation.

Acknowledgment: The work presented in this paper comes from the project titled: Step Change in Agro-Food Logistics Ecosystems (SCALE) sponsored by Interreg IVB North-West Europe. Project SCALE aims to increase NWE economic competitiveness and improve environmental sustainability of food and drink supply chain and logistics.

\section{References}

[1] Ageron, B., Gunasekaran, A., Spalanzani, A., (2012). Sustainable supply management: An empirical study, International Journal of Production Economics, 140-1, 168-182.

[2] Ahumada, O., Villalobos, JR., (2009). Application of planning models in the agri-food supply chain: A review, European Journal of Operational Research 196 (1), 1-20.

[3] Aivazidou, E., Tsolakis, N., Vlachos, D., Iakovou., E., (2015). Water Footprint Management Policies for Agrifood Supply Chains: A Critical Taxonomy and a System Dynamics Modelling Approach. Chimical Engineering Transactions, 43.

[4] Amiri, A., (2006). Designing a distribution network in a supply chain system: Formulation and efficient solution procedure. European Journal of Operational Research, 171, 567-576.

[5] Aramyan, L., Ondersteijn, Van Kooten, O., Lansink, O.A. (2006). Performance Indicators in Agri-Food Production Chains. In Ondersteijn, C.J.M. et al. (eds.), Quantifying the agrifood Supply Chain, 49-66, Springer. Netherlands.

[6] Azadi, M., Jafarian, M., Saen, R.F., Mirhedayatian, S.M., (2015). A new fuzzy DEA model for evaluation of efficiency and effectiveness of suppliers in sustainable supply chain management context, Computers \& Operations Research, 54, 274-285.

[7] Bai, C., Sarkis, J., (2010). Integrating sustainability into supplier selection with grey system and rough set methodologies. International Journal of Production Economics 124 (1), 252-264.

[8] Bakas, I. (2012). Food and Greenhouse Gas (GHG) Emissions [Online]. Available: http://www.scp-knowledge.eu/sites/default/files/KU_Food_GHG_emissions.

[9] Battini, D., Bortolini, M., Faccio, M., Gamberi, M., Pilati, F., (2013). Bi-objective optimization of environmental impact and cost in multi-modal distribution networks. International Conference on Production Research 1- 828 July - 1 August 2013 Iguassu Falls, Brazil,

[10] Battini D., Bortolini M., Faccio M., Gamberi M., Pilati F., Regattieri A., Energy and cost optimisation in multi-modal fresh food distribution network, in: 22nd International Conference on Production Research, BRASIL, Iguassu Falls, July 28th - August 1st, 2013, pp.1-8. 
[11] Bryceson, K. P. and Smith, C. S. (2008). Abstraction and Modelling of Agri-Food Chains as Complex Decision Making Systems. In: Melanie Fritz, Ursula Rickert and Gerhard Schiefer, EAAA Series on Systems Dynamics and Innovation in Food Networks. European Association of Agricultural Economists1 10th Seminar, Innsbruck-Igls, Austria, (147-159).

[12] Chang, T. C., Lin, S. J., (1999). Grey relation analysis of carbon dioxide emissions from industrial production and energy uses in Taiwan, Journal of Environmental Management, 56, $247-257$.

[13] Chen, C. T., Lin, C. T., Huang, S. F., (2006). A fuzzy approach for supplier evaluation and selection in supply chain management. International Journal of Production Economics, 102, 289301.

[14] Collette, Y. Siarry, P. (2004), Multi-objective Optimization: Principles and Case Studies, Springer.

[15] Deng, J. (1982). Control problems of grey systems. Systems and Control Letters, 5(2), 288294.

[16] Dulmin, R., Mininno, V., (2003). Supplier selection using a multi-criteria decision aid method. Journal of Purchasing \& Supply Management 9, 177-187.

[17] Eskigun, E., Uzsoy, R., Preckel, P.V., Beaujon, G. , Krishnan, S., Tew, J.D., (2005). Outbound supply chain network design with mode selection, lead times and capacitated vehicle distribution centers, European Journal of Operational Research, 165, 182-206.

[18] Eskandarpour, M., Dejax, P., Miemczyk., J., and Péton., O., (2015). Sustainable supply chain network design: An optimization-oriented review, Omega 54, 11-32.

[19] Fahimnia B., Bell MGH., Hensher DA. and Sarkis J. (2015). The Future of Green Logistics and Transportation in Green Logistics and Transportation: A Sustainable Supply Chain Perspective, ed. B. Fahimnia, M.G.H. Bell, D.A. Hensher \& J. Sarkis, Springer International Publishing, Cham, Switzerland, pp. 193-97.

[20] Fernández-Castro, A.S., Jiménez, M., (2005). PROMETHEE: An extension through fuzzy mathematical programming. Journal of the Operational Research Society 56, 119-122.

[21] Fisher, M.L. (1985). An applications oriented guide to Lagrangian relaxation, Interfaces, 15, $10-21$.

[22] Govindan, K., Jafarian, A., Nourbakhsh, V., (2015), Bi-objective integrating sustainable order allocation and sustainable supply chain network strategic design with stochastic demand using a novel robust hybrid multi-objective metaheuristic, Computers \& Operations Research, $112-130$.

[23] Govindan, K., Cheng, T.C.E., (2015). Sustainable supply chain management: Advances in operations research perspective, Computers \& Operations Research, 54, 177-179.

[24] Gumus, A. T., (2009). Evaluation of hazardous waste transportation firms by using a two step fuzzy-AHP and TOPSIS methodology. Expert Systems with Applications, 36, 4067-4074. 
[25] Gunasekaran, A., and Spalanzani, A., (2012), Sustainability of manufacturing and services: Investigations for research and applications, International Journal of Production Economics, 140$1,35-47$.

[26] Gunasekaran, A, Irani, Z., Papadopoulos, T., (2013). Modelling and analysis of sustainable operations management: certain investigations for research and applications. Journal of the Operational Research Society 65.6, 806-823.

[27] Gunasekaran, A., and Irani, Z., (2014). Sustainable Operations Management: design, modelling and analysis. Journal of the Operational Research Society, 65.6, 801-805.

[28] Gunasekaran, A., Subramanian, N., Rahman, S., (2015). Green supply chain collaboration and incentives: Current trends and future directions, Transportation Research Part E: Logistics and Transportation Review, 74, 1-10, 1366-5545.

[29] Hajidimitriou, Y.A., Georgiou, A.C., (2002). A goal programming model for partner selection decisions in international joint ventures. European Journal of Operational Research 138 (3), 649-662.

[30] Higgs, G. (2006). Integrating multi-criteria techniques with geographical information systems in waste facility location to enhance public participation, Waste Management Research, 24, 105-117.

[31] Hinojosa, Y., Puerto, J., Fernández, F.R., (2000). A multi-period two-echelon multi-commodity capacitated plant location problem, European Journal of Operational Research, 123, 271-291.

[32] International Resource Panel, (2010). Priority products and materials: assessing the environmental impacts of consumption and production. United Nations Environment Programme.

[33] Karpak, B., Kumcu, E., Kasuganti, R.R., (2001). Purchasing materials in the supply chain: Managing a multi-objective task. European Journal of Purchasing and Supply Management 7 (3), 209-216.

[34] Kurttila, M., Pesonen, M., Kangas, J., Kajanus, M., (2000). Utilizing the analytic hierarchy process (AHP) in SWOT analysis - a hybrid method and its application to a forestcerti fi cation case. Forest Policy and Economics 1, 41-52.

[35] Liu, S., Lazaros, Papageorgiou,G., (2012), Multiobjective optimisation of production, distribution and capacity planning of global supplychains in the process industry Omega In Press, Corrected Proof.

[36] Lu, Z., Bostel, N., (2007). A facility location model for logistics systems including reverse flows: The case of remanufacturing activities, Computers \& Operations Research, 34, 299-322.

[37] Mele, F.D., Guillén-Gosálbez, G, Jiménez, L., Bandoni, A., (2010), Optimal Planning of the Sustainable Supply Chain for Sugar and Bioethanol Production, Computer Aided Chemical Engineering, 27, 597-602, 10th International Symposium on Process Systems Engineering: Part A. 
[38] Mendoza, G.A., Prabhu, R., (2005). Combining participatory modelling and multi-criteria analysis for community-based forest management. Forest Ecology and Management, 207, 145156.

[39] Miranda, P.A., Garrido, R.A., (2004). Incorporating inventory control decisions into a strategic distribution network design model with stochastic demand, Transportation Research Part E: Logistics and Transportation Review, 40, 183-207.

[40] Norese, M.F., (2006). ELECTRE III as a support for participatory decision-making on the localisation of waste-treatment plants, Land Use Policy, 23, 76- 85.

[41] Pirkul, H., Jayaraman, V., (1998). A Multi-Commodity , Multi-Plant , Capacitated Facility Location Problem: Formulation and Efficient Heuristic solution, Computers \& Operational Research, 25, 869-878.

[42] Pishvaee, M.S, Razmi, J., (2012). Environmental supplychain network design using multiobjective fuzzy mathematical programming. Applied Mathematical Modelling, 36, 8, 3433-3446.

[43] Saaty, T.L. (1980). Analytic Hierarchy Process, Planning, Priority Setting, Resource Allocation.

[44] Santoso, T. , Ahmed, S., Goetschalckx, M., Shapiro, A., (2005). A stochastic programming approach for supply chain network design under uncertainty, European Journal of Operational Research, 167, 96-115.

[45] SCALE project, INTERREG VI B NORTH WEST EUROPE (http://sfcplatform.eu/).

[46] Seuring, S., Müller, M., (2008). From a literature review to a conceptual framework for sustainable supply chain management. Journal of Cleaner Production, 16-15, 1699-1710.

[47] Shaw, K., Shankara, R., Yadava, S.S, Thakurb, L.S., (2012). Supplier selection using fuzzy AHP and fuzzy multi-objective linear programming for developing low carbon supply chain, Expert Systems with Applications, 39-9, 8182-8192.

[48] Shukla, N., Choudhary, A., Prakash, P.K.S., Fernandese, K.J., and Tiwarif, M.K., (2013). Algorithm portfolios for logistics optimization considering stochastic demands and mobility allowance, International Journal of Production Economics, 141-1, 146-166.

[49] Shukla, N., Tiwaric, M.K., and Ceglarekad, D., (2013). Genetic-algorithms-based algorithm portfolio for inventory routing problem with stochastic demand, International Journal of Production Research, 51-1, 118-137.

[50] Shukla, M., Shuklaa, N., Tiwarib, M. K., and Chanc, F. T. S., (2009). Integrated model for the batch sequencing problem in a multi-stage supply chain: an artificial immune system based approach, International Journal of Production Research, 47-4, 1015-1037.

[51] Sourirajan, K., Ozsen, L., Uzsoy, R. (2007) . A single-product network design model with lead time and safety stock considerations, IIE Transactions, 39, 411-424.

[52] Soysal, M., Bloemhof-Ruwaard, J.M., Meuwissen, M.P.M., and. van der Vorst, J.G.A.J (2012), A Review on Quantitative Models for Sustainable Food Logistics Management. Int. J. Food System Dynamics 3 (2), 136-155. 
[53] Tsolakis, N.K., Keramydas, C.A., Toka, A.K., Aidonis, D.A., Iakovou, E.T., (2014). Agrifood supply chain management: A comprehensive hierarchical decision-making framework and a critical taxonomy. Biosystems Engineering, Volume 120, April 2014, Pages 47-64.

[54] Tuzkaya, G., Önüt, S., Tuzkaya, U.R., Gülsün, B. (2008). An analytic network process approach for locating undesirable facilities: an example from Istanbul, Turkey, Journal of Environmental Management, 88, 970-982.

[55] Tuzkaya, G., Ozgen, A., Ozgen, D., Tuzkaya, U. R. (2009). Environmental performance evaluation of suppliers: A hybrid fuzzy multi-criteria decision approach. International Journal of Environmental Science and Technology, 6, 477-490.

[56] Ulutas, A., Shukla, N., Kiridenaa, S., and Gibson, P., (2016). A utility-driven approach to supplier evaluation and selection: empirical validation of an integrated solution framework, International Journal of Production Research, 54-5, 1554-1567.

[57] UNESCO, 2009, Water in a Changing World: The United Nations World Water Development Report 3, accessed 07.10.2014.

[58] Validi, S., Bhattacharya, A., Byrne, P.J. (2015). A solution method for a two-layer sustainable supply chain distribution model, Computers \& Operations Research, 54, 204-217.

[59] Van der Vorst, J.G.A.J., (2006). Performance Measurement in Agro-food Supply-Chain Networks, Quantifying the agri-food supply chain.

[60] Vermeulen, S. J., Campbell, B. M. \& Ingram, J. S. I (2012). Annu. Rev. Environ. Resour. 37, $195-222$.

[61] Wang, J.J., Yang, D.L., (2007). Using a hybrid multi-criteria decision aid method for information systems outsourcing. Computers \& Operations Research 34, 3691- 3700.

[62] William, H. (2007). Combining analytic hierarchy process and goal programming for logistics distribution network design. IEEE International Conference on Systems, Man, and Cybernetics, 714-719.

[63] Xie, G., (2015). Modeling decision processes of a green supply chain with regulation on energy saving level, Computers \& Operations Research, 54, 266-273.

[64] Yager, R.R., (1988). On ordered weighted averaging aggregation operators in multicriteria decisionmaking, IEEE Trans. Syst. Man Cybern, 18 (1), 183-190.

[65] Yong, D., (2006). Plant location selection based on fuzzy TOPSIS. International Journal of Advanced Manufacturing Technology, 28, 839-844.

[66] Zhang, Q., Shah, N., Wassick, J., Helling, R., Egerschot P., V., (2014). Sustainable supply chain optimisation: An industrial case study. Computers and Industrial Engineering, 74, 68-83. 